Article

\title{
Ion Channel Expression in Human Melanoma Samples: In Silico Identification and Experimental Validation of Molecular Targets
}

\author{
Daniela D'Arcangelo ${ }^{1}$, Francesca Scatozza ${ }^{1}$, Claudia Giampietri ${ }^{2}{ }^{(1)}$, Paolo Marchetti ${ }^{3}$, \\ Francesco Facchiano ${ }^{4}$ and Antonio Facchiano ${ }^{1, *(D)}$ \\ 1 Istituto Dermopatico dell'Immacolata (IDI-IRCCS), 00167 Rome, Italy; d.darcangelo@idi.it (D.D.); \\ f.scatozza@idi.it (F.S.) \\ 2 Department of Anatomy, Histology, Forensic Medicine and Orthopedics, Unit of Histology and Medical \\ Embryology, Sapienza University of Rome, 00161 Rome, Italy; claudia.giampietri@uniroma1.it \\ 3 Medical Oncology, Sapienza, University of Rome, 00161 Rome, Italy; paolo.marchetti@uniroma1.it \\ 4 Department of Oncology and Molecular Medicine, Istituto Superiore di Sanità (ISS), 00161 Rome, Italy; \\ francesco.facchiano@iss.it \\ * Correspondence: a.facchiano@idi.it
}

Received: 5 March 2019; Accepted: 23 March 2019; Published: 29 March 2019

\begin{abstract}
Expression of 328 ion channel genes was investigated, by in silico analysis, in 170 human melanoma samples and controls. Ninety-one members of this gene-family (i.e., about $28 \%$ ) show a significant $(p<0.05)$ differential expression in melanoma- vs. nevi-biopsies, taken from the GEO database. ROC (receiver operating characteristic) analysis selected 20 genes as potential markers showing the highest discrimination ability of melanoma vs. nevi (AUC $>0.90$ and $p<0.0001$ ). These 20 genes underwent a first in silico-validation round in an independent patients-dataset from GEO. A second-in silico-validation step was then carried out on a third human dataset in Oncomine. Finally, five genes were validated, showing extremely high sensitivity and specificity in melanoma detection (>90\% in most cases). Such five genes (namely, SCNN1A, GJB3, KCNK7, GJB1, KCNN2) are novel potential melanoma markers or molecular targets, never previously related to melanoma. The "druggable genome" analysis was then carried out. Miconazole, an antifungal drug commonly used in clinics, is known to target $K C N N 2$, the best candidate among the five identified genes. Miconazole was then tested in vitro in proliferation assays; it dose-dependently inhibited proliferation up to $90 \%$ and potently induced cell-death in A-375 and SKMEL-28 melanoma cells, while it showed no effect in control cells. Moreover, specific silencing of KCNN2 ion channel was achieved by siRNA transfection; under such condition miconazole strongly increases its anti-proliferative effect. In conclusion, the present study identified five ion channels that can potentially serve as sensitive and specific markers in human melanoma specimens and demonstrates that the antifungal drug miconazole, known to target one of the five identified ion channels, exerts strong and specific anti-melanoma effects in vitro.
\end{abstract}

Keywords: KCNN2; ion channels; melanoma; miconazole

\section{Introduction}

Ion channels play a key role in the physiology of any cell- and tissue-type; this makes ion channels ideal potential therapeutic targets [1]. In a way, they represent the tollbooths filtering the molecular flux on the highways connecting the intracellular to the extracellular environment. Given the exceptional role of ion channels in controlling almost any cellular function, drugs targeting ion channels may cover a market of several billion USD [2]. Thus, it is no surprise the large interest pharmaceutical companies 
give to ion channels as molecular targets in many different pathological conditions, such as pain relief [3], cardiovascular diseases [4-6], diabetes [7], infectious diseases such as Hepatitis C virus [8] and influenza virus [9], CNS diseases [10-13], and cystic fibrosis [14,15]. Increasing interest is currently given to ion channels in cancers since they have been indicated as potential drug targets in many cancer conditions [16-18]. We have recently reported an extensive ion channels expression analysis in several solid tumors demonstrating relevant and significant alterations in bladder cancer, glioblastoma, melanoma, breast cancer, and lung carcinoma, in more than 3000 patients [19], further indicating ion channels as potential therapeutic targets or molecular markers in cancer field. Indeed, ion channels expression has been related to clinical outcome in breast cancer [20] and the role of different ion channels has been recently demonstrated in lung cancer [21,22] as well as prostate cancer [23-25]. Mutation in glutamate receptors have been related to increased survival in malignant melanoma [26]. In addition, directly targeting mitochondrial potassium channels exerts a potent antitumor effect in vivo in melanoma and in pancreatic adenocarcinoma mouse models [27]. These data confirm the crucial role ion channels play in many cancer conditions including melanoma and prompted us to investigate the expression level of 328 ion channels in human melanoma samples looking for ion channels genes acting as potential markers and molecular targets in a melanoma set up.

\section{Results}

The general procedure followed in the present study is summarized in Figure 1.

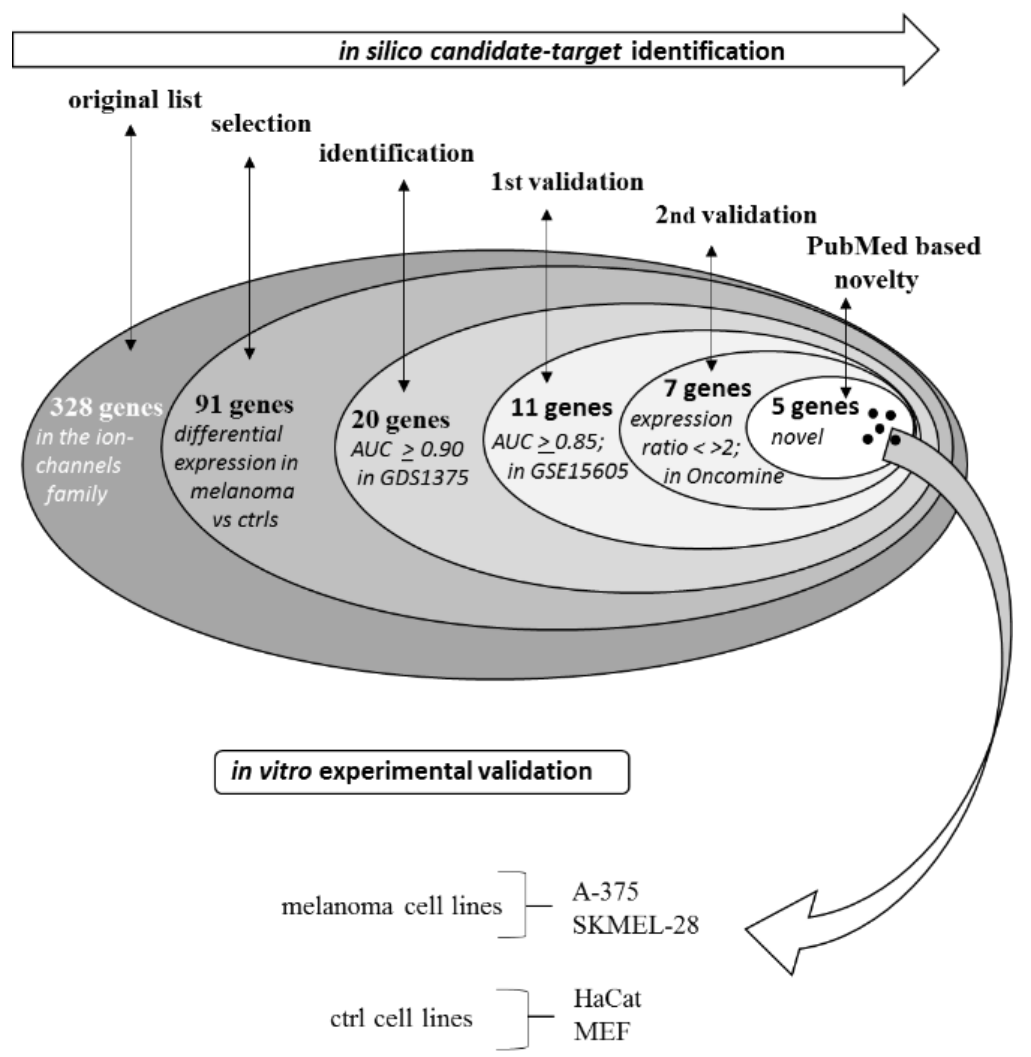

Figure 1. Procedure for the selection of the five best candidates and for the experimental validation.

\subsection{Selection Phase}

The expression level of each of the 328 genes reported in Table 1 was compared in melanoma vs. controls. Table 2 reports the 91 genes showing a statistically different expression level in melanoma vs. controls $(p<0.05)$. The genes are reported in order of their $p$ value, starting from the most significant $\left(p>10^{-18}\right)$ down to the $p>0.05$ threshold. Indeed, more than half of such genes fall within the $p$ value below the $10^{-4}$ range, highlighting that a relevant number of members of the ion channels family are 
strongly and significantly modified in melanoma biopsies. For each gene, the computed fold change in melanoma vs. controls is also indicated, along with the AUC (area under the curve) according to the ROC (receiver operating characteristic) analysis. AUC indicates the ability to discriminate melanoma from nevi samples. Several genes show an extremely significant $p$ value combined with a high fold change and high AUC value. Genes showing AUC $>0.90$ and a $p<0.0001$, i.e., a significant discriminating ability of at least $90 \%$, were selected and are reported in Table 3 , sorted according to the AUC level.

The analysis was carried out in GDS1375 dataset from the GEO database, containing data from 45 melanoma biopsies and 18 normal skin biopsies.

\subsubsection{First-Round Validation Step}

The 20 genes having AUC $\geq 0.90$ according to the expression levels reported in the GEO dataset GDS1375 were then analyzed in a different human samples dataset (GEO GSE15605) presenting data from 62 patients. Eleven genes showing an AUC level $\geq 0.85$ in the second dataset were selected as genes validated in the 1st round validation, namely: SCNN1A, ANO1, GJA1, GJB3, SCNN1B, GABRE, KCNK7, KCND3, KCNK1, GJB1, KCNN2 (see Table 3).

\subsubsection{Second-Round Validation Step}

The 11 genes analyzed in GDS1375 and first-round validated in GSE15605 were then analyzed in a third dataset, namely the Riker dataset from Oncomine database. The seven genes showing an expression ratio in melanoma/controls $<0.5$ or $>2$ were then identified, namely: SCNN1A, ANO1, GJB3, GABRE, KCNK7, GJB1, KCNN2 (see Table 3) and were considered second-round validated. Any known relation of these five genes with melanoma was then investigated according to a PubMed search, and they were all selected as novel genes:

SCNN1A ("Sodium Channel Epithelial 1 Alpha Subunit", sodium channel, non-voltage-gated, amiloride sensitive),

GJB3 ("Gap Junction Protein Beta 3", gap-junction component, connexin gene family member),

KCNK7 ("Potassium Two Pore Domain Channel Subfamily K Member 7", potassium channel),

GJB1 ("Gap Junction Protein Beta 1", gap-junction component, connexin gene family member),

KCNN2 ("Potassium Calcium-Activated Channel Subfamily N Member 2", potassium channel).

No co-occurrence of their gene name or synonymous names is reported with "melanoma" word, in any field in PubMed searches (see Table 3, right end-side column). These five genes were then selected as the best novel candidates as melanoma markers and melanoma molecular targets. Figure 2 depicts the corresponding ROC curves of the five best candidates computed on the expression values reported in the GDS 1375 dataset. In all cases an AUC $>0.90$ and $p<0.0001$ is reported, i.e., a very high and significant ability to discriminate melanoma from healthy controls samples. The sensitivity and specificity values were computed as reported in the Methods section, indicating: 92\% specificity and $97.7 \%$ sensitivity for SCNN1A; $96 \%$ specificity and 91\% sensitivity for GJB3; $84 \%$ specificity and 97.7 sensitivity for KCNK7; $96 \%$ specificity and $84.4 \%$ sensitivity for GJB1; $100 \%$ specificity and $82.2 \%$ sensitivity for KCNN2. 
Table 1. Ion channels genes investigated in the present study, selected according to HUGO Gene Nomenclature Committee at https:/ /www.genenames.org/cgi-bin/ genefamilies/.

\begin{tabular}{|c|c|c|c|c|c|c|c|c|c|c|c|}
\hline No. & Gene Name & No. & Gene Name & No. & Gene Name & No. & Gene Name & No. & Gene Name & No. & Gene Name \\
\hline 1 & ANO1 & 56 & CACNG5 & 111 & GABRB1 & 166 & GRIN2D & 221 & KCNJ2 & 276 & $P 2 R X 6$ \\
\hline 2 & ANO10 & 57 & CACNG6 & 112 & GABRB2 & 167 & GRIN3A & 222 & KCNJ3 & 277 & $P 2 R X 7$ \\
\hline 3 & ANO2 & 58 & CACNG7 & 113 & GABRB3 & 168 & GRIN3B & 223 & KCNJ4 & 278 & PKD2 \\
\hline 4 & ANO3 & 59 & CACNG8 & 114 & GABRD & 169 & HCN1 & 224 & KCNJ5 & 279 & PKD2L1 \\
\hline 5 & ANO4 & 60 & CATSPER1 & 115 & GABRE & 170 & HCN2 & 225 & KCNJ6 & 280 & $P K D 2 L 2$ \\
\hline 6 & ANO5 & 61 & CATSPER2 & 116 & GABRG1 & 171 & HCN3 & 226 & KCNJ8 & 281 & RYR1 \\
\hline 7 & ANO6 & 62 & CATSPER3 & 117 & GABRG2 & 172 & HCN4 & 227 & KCNJ9 & 282 & $R Y R 2$ \\
\hline 8 & ANO7 & 63 & CATSPER4 & 118 & GABRG3 & 173 & HTR3A & 228 & KCNK1 & 283 & $R Y R 3$ \\
\hline 9 & ANO8 & 64 & CATSPERB & 119 & GABRP & 174 & HTR3B & 229 & KCNK10 & 284 & SCN10A \\
\hline 10 & ANO9 & 65 & CATSPERD & 120 & GABRQ & 175 & HTR3C & 230 & KCNK12 & 285 & SCN11A \\
\hline 11 & $A Q P 1$ & 66 & CATSPERG & 121 & GABRR1 & 176 & HTR3D & 231 & KCNK13 & 286 & SCN1A \\
\hline 12 & $A Q P 10$ & 67 & CFTR & 122 & GABRR2 & 177 & HTR3E & 232 & KCNK15 & 287 & SCN1B \\
\hline 13 & $A Q P 11$ & 68 & CHRNA1 & 123 & GABRR3 & 178 & HVCN1 & 233 & KCNK16 & 288 & $S C N 2 A$ \\
\hline 14 & $A Q P 12 A$ & 69 & CHRNA10 & 124 & GJA1 & 179 & ITPR1 & 234 & KCNK17 & 289 & $S C N 2 B$ \\
\hline 15 & $A Q P 12 B$ & 70 & CHRNA2 & 125 & GJA10 & 180 & ITPR2 & 235 & KCNK18 & 290 & $S C N 3 A$ \\
\hline 16 & $A Q P 2$ & 71 & CHRNA3 & 126 & GJA3 & 181 & ITPR3 & 236 & KCNK2 & 291 & SCN3B \\
\hline 17 & $A Q P 3$ & 72 & CHRNA4 & 127 & GJA4 & 182 & KCNA1 & 237 & KCNK3 & 292 & SCN4A \\
\hline 18 & $A Q P 4$ & 73 & CHRNA5 & 128 & GJA5 & 183 & KCNA10 & 238 & KCNK4 & 293 & $S C N 4 B$ \\
\hline 19 & $A Q P 5$ & 74 & CHRNA6 & 129 & GJA6P & 184 & KCNA2 & 239 & KCNK5 & 294 & SCN5A \\
\hline 20 & $A Q P 6$ & 75 & CHRNA7 & 130 & GJA8 & 185 & KCNA3 & 240 & KCNK6 & 295 & $S C N 8 A$ \\
\hline 21 & $A Q P 7$ & 76 & CHRNA9 & 131 & GJA9 & 186 & KCNA4 & 241 & KCNK7 & 296 & SCN9A \\
\hline 22 & $A Q P 8$ & 77 & CHRNB1 & 132 & GJB1 & 187 & KCNA5 & 242 & KCNK9 & 297 & SCNN1A \\
\hline 23 & $A Q P 9$ & 78 & CHRNB2 & 133 & GJB2 & 188 & KCNA6 & 243 & KCNMA1 & 298 & SCNN1B \\
\hline 24 & ASIC1 & 79 & CHRNB3 & 134 & GJB3 & 189 & KCNA7 & 244 & KCNN1 & 299 & SCNN1D \\
\hline 25 & ASIC2 & 80 & CHRNB4 & 135 & GJB4 & 190 & KCNB1 & 245 & KCNN2 & 300 & SCNN1G \\
\hline 26 & ASIC3 & 81 & CHRND & 136 & GJB5 & 191 & KCNB2 & 246 & KCNN3 & 301 & TPCN1 \\
\hline 27 & ASIC4 & 82 & CHRNE & 137 & GJB6 & 192 & KCNC1 & 247 & KCNN4 & 302 & TPCN2 \\
\hline 28 & ASIC5 & 83 & CHRNG & 138 & GJB7 & 193 & KCNC2 & 248 & KCNQ1 & 303 & TRPA1 \\
\hline
\end{tabular}


Table 1. Cont

\begin{tabular}{|c|c|c|c|c|c|c|c|c|c|c|c|}
\hline No. & Gene Name & No. & Gene Name & No. & Gene Name & No. & Gene Name & No. & Gene Name & No. & Gene Name \\
\hline 29 & BEST1 & 84 & CLCN1 & 139 & GJC1 & 194 & KCNC3 & 249 & KCNQ2 & 304 & TRPC1 \\
\hline 30 & BEST2 & 85 & CLCN2 & 140 & GJC2 & 195 & KCNC4 & 250 & KCNQ3 & 305 & TRPC2 \\
\hline 31 & BEST3 & 86 & CLCN3 & 141 & GJC3 & 196 & KCND1 & 251 & KCNQ4 & 306 & TRPC3 \\
\hline 32 & BEST4 & 87 & CLCN4 & 142 & GJD2 & 197 & KCND2 & 252 & KCNQ5 & 307 & TRPC4 \\
\hline 33 & BSND & 88 & CLCN5 & 143 & GJD3 & 198 & KCND3 & 253 & KCNS1 & 308 & TRPC5 \\
\hline 34 & CACNA1A & 89 & CLCN6 & 144 & GJD4 & 199 & KCNF1 & 254 & KCNS2 & 309 & TRPC6 \\
\hline 35 & CACNA1B & 90 & CLCN7 & 145 & GJE1 & 200 & KCNG1 & 255 & KCNS3 & 310 & TRPC7 \\
\hline 36 & CACNA1C & 91 & CLCNKA & 146 & GLRA1 & 201 & KCNG2 & 256 & KCNT1 & 311 & TRPM1 \\
\hline 37 & CACNA1D & 92 & CLCNKB & 147 & GLRA2 & 202 & KCNG3 & 257 & KCNT2 & 312 & TRPM2 \\
\hline 38 & CACNA1E & 93 & CLIC1 & 148 & GLRA3 & 203 & KCNG4 & 258 & KCNU1 & 313 & TRPM3 \\
\hline 39 & CACNA1F & 94 & CLIC2 & 149 & GLRA4 & 204 & KCNH1 & 259 & KCNV1 & 314 & TRPM4 \\
\hline 40 & CACNA1G & 95 & CLIC3 & 150 & GLRB & 205 & $\mathrm{KCNH} 2$ & 260 & KCNV2 & 315 & TRPM5 \\
\hline 41 & CACNA1H & 96 & CLIC4 & 151 & GRIA1 & 206 & KCNH3 & 261 & LRRC $8 A$ & 316 & TRPM6 \\
\hline 42 & CACNA1I & 97 & CLIC5 & 152 & GRIA2 & 207 & KCNH4 & 262 & LRRC $8 B$ & 317 & TRPM7 \\
\hline 43 & CACNA1S & 98 & CLIC6 & 153 & GRIA3 & 208 & KCNH5 & 263 & $L R R C 8 C$ & 318 & TRPM8 \\
\hline 44 & CACNA2D1 & 99 & CNGA1 & 154 & GRIA4 & 209 & KCNH6 & 264 & LRRC $8 D$ & 319 & TRPV1 \\
\hline 45 & CACNA2D2 & 100 & CNGA2 & 155 & GRID1 & 210 & KCNH7 & 265 & LRRC8E & 320 & TRPV2 \\
\hline 46 & CACNA2D3 & 101 & CNGA3 & 156 & GRID2 & 211 & KCNH8 & 266 & MCOLN1 & 321 & TRPV3 \\
\hline 47 & CACNA2D4 & 102 & CNGA4 & 157 & GRIK1 & 212 & KCNJ1 & 267 & MCOLN2 & 322 & TRPV4 \\
\hline 48 & CACNB1 & 103 & CNGB1 & 158 & GRIK2 & 213 & KCNJ10 & 268 & MCOLN3 & 323 & TRPV5 \\
\hline 49 & CACNB2 & 104 & CNGB3 & 159 & GRIK3 & 214 & KCNJ11 & 269 & MIP & 324 & TRPV6 \\
\hline 50 & CACNB3 & 105 & GABRA1 & 160 & GRIK4 & 215 & KCNJ12 & 270 & NALCN & 325 & $V D A C 1$ \\
\hline 51 & CACNB4 & 106 & GABRA2 & 161 & GRIK5 & 216 & KCNJ13 & 271 & $P 2 R X 1$ & 326 & $V D A C 2$ \\
\hline 52 & CACNG1 & 107 & GABRA3 & 162 & GRIN1 & 217 & KCNJ14 & 272 & $P 2 R X 2$ & 327 & $V D A C 3$ \\
\hline 53 & CACNG2 & 108 & GABRA4 & 163 & GRIN2A & 218 & KCNJ15 & 273 & $P 2 R X 3$ & 328 & $Z A C N$ \\
\hline 54 & CACNG3 & 109 & GABRA5 & 164 & GRIN2B & 219 & KCNJ16 & 274 & $P 2 R X 4$ & & \\
\hline 55 & CACNG4 & 110 & GABRA6 & 165 & GRIN2C & 220 & KCNJ18 & 275 & $P 2 R X 5$ & & \\
\hline
\end{tabular}


Table 2. List of ion channels genes showing differential expression in nevi vs. melanoma $(p<0.05)$, sorted according to the AUC value. The analysis was carried out in the GEO GDS1375 dataset.

\begin{tabular}{|c|c|c|c|c|c|c|c|c|c|c|c|}
\hline $\begin{array}{c}\text { No. } \\
1\end{array}$ & $\begin{array}{c}\text { Gene } \\
\text { Name }\end{array}$ & $\begin{array}{c}\begin{array}{c}\text { Test Nevi vs. } \\
\text { Melanoma }\end{array} \\
8.7 \times 10^{-18} \\
\end{array}$ & \multicolumn{2}{|c|}{$\begin{array}{c}\text { Ratio Melanoma } \\
\text { vs. Nevi }\end{array}$} & $\begin{array}{l}\text { AUC } \\
0.98 \\
\end{array}$ & $\begin{array}{c}\text { No. } \\
47\end{array}$ & $\begin{array}{c}\text { Gene Name } \\
C A C N B 2\end{array}$ & $\begin{array}{c}t \text { Test Nevi vs. } \\
\text { Melanoma }\end{array}$ & \multicolumn{2}{|c|}{$\begin{array}{c}\text { Ratio Melanoma } \\
\text { vs. Nevi }\end{array}$} & $\begin{array}{r}\text { AUC } \\
0.73\end{array}$ \\
\hline 2 & KCNK7 & $1.8 \times 10^{-17}$ & 0.081 & $\nabla$ & 0.94 & 48 & TRPV6 & $1.9 \times 10^{-3}$ & 0.576 & $\nabla$ & 0.65 \\
\hline 4 & SCNN1B & $1.4 \times 10^{-14}$ & 0.313 & $\nabla$ & 0.96 & 50 & $S C N 3 A$ & $2.2 \times 10^{-3}$ & 0.382 & $\boldsymbol{\nabla}$ & 0.64 \\
\hline 5 & GABRE & $2.3 \times 10^{-13}$ & 0.203 & $\nabla$ & 0.95 & 51 & GRIN2A & $2.3 \times 10^{-3}$ & 0.619 & $\nabla$ & 0.69 \\
\hline 7 & CLIC1 & $1.9 \times 10^{-12}$ & 1.738 & 4 & 0.95 & 53 & GABRB1 & $3.0 \times 10^{-3}$ & 0.698 & $\nabla$ & 0.69 \\
\hline 8 & KCND3 & $2.0 \times 10^{-11}$ & 0.487 & $\nabla$ & 0.94 & 54 & GJB4 & $3.7 \times 10^{-3}$ & 0.588 & $\nabla$ & 0.63 \\
\hline 9 & KCNK1 & $8.6 \times 10^{-11}$ & 0.269 & $\nabla$ & 0.93 & 55 & CACNB4 & $4.3 \times 10^{-3}$ & 0.474 & $\nabla$ & 0.66 \\
\hline 10 & GRIA1 & $8.7 \times 10^{-11}$ & 0.1049 & $\nabla$ & 0.93 & 56 & CACNA11 & $5.0 \times 10^{-3}$ & 0.629 & $\nabla$ & 0.70 \\
\hline 11 & $V D A C 1$ & $2.0 \times 10^{-10}$ & 1.8 & 4 & 0.96 & 57 & KCNK2 & $5.0 \times 10^{-3}$ & 0.512 & $\nabla$ & 0.64 \\
\hline 15 & ITPR3 & $1.1 \times 10^{-9}$ & 2.311 & 4 & 0.93 & 61 & GRIN2D & $6.7 \times 10^{-3}$ & 1.922 & 4 & 0.75 \\
\hline 16 & $R Y R 1$ & $1.8 \times 10^{-9}$ & 0.2414 & $\nabla$ & 0.81 & 62 & CLIC4 & $6.8 \times 10^{-3}$ & 0.671 & $\nabla$ & 0.69 \\
\hline 17 & GJA1 & $2.1 \times 10^{-9}$ & 0.086 & $\nabla$ & 0.98 & 63 & CACNA1S & $7.7 \times 10^{-3}$ & 1.91 & 4 & 0.77 \\
\hline 18 & KCNJ13 & $1.9 \times 10^{-8}$ & 0.266 & $\nabla$ & 0.86 & 64 & CATSPER2 & $8.1 \times 10^{-3}$ & 0.677 & $\nabla$ & 0.75 \\
\hline 19 & TRPV2 & $3.0 \times 10^{-8}$ & 1.77 & 4 & 0.88 & 65 & GABRP & $8.1 \times 10^{-3}$ & 0.3014 & $\nabla$ & 0.69 \\
\hline 20 & GJB1 & $3.4 \times 10^{-8}$ & 2.643 & 4 & 0.93 & 66 & GJA4 & $9.0 \times 10^{-3}$ & 0.5357 & $\nabla$ & 0.68 \\
\hline 21 & CLIC3 & $4.0 \times 10^{-8}$ & 0.118 & $\nabla$ & 0.85 & 67 & KCNJ15 & $9.0 \times 10^{-3}$ & 0.506 & $\boldsymbol{\nabla}$ & 0.64 \\
\hline 22 & $L R R C 8 B$ & $4.4 \times 10^{-8}$ & 0.459 & $\nabla$ & 0.90 & 68 & CNGB3 & $1.0 \times 10^{-2}$ & 0.63 & $\nabla$ & 0.69 \\
\hline 23 & HCN2 & $2.1 \times 10^{-7}$ & 3.88 & 4 & 0.89 & 69 & SCNN1D & $1.0 \times 10^{-2}$ & 0.735 & $\nabla$ & 0.69 \\
\hline
\end{tabular}


Table 2. Cont.

\begin{tabular}{|c|c|c|c|c|c|c|c|c|c|c|c|}
\hline \multirow{2}{*}{$\begin{array}{l}\text { No. } \\
25\end{array}$} & \multirow{2}{*}{$\begin{array}{c}\begin{array}{c}\text { Gene } \\
\text { Name }\end{array} \\
B E S T 2\end{array}$} & \multirow{2}{*}{$\begin{array}{c}t \begin{array}{c}t \text { Test Nevi vs. } \\
\text { Melanoma }\end{array} \\
3.6 \times 10^{-7}\end{array}$} & \multicolumn{2}{|c|}{$\begin{array}{c}\text { Ratio Melanoma } \\
\text { vs. Nevi }\end{array}$} & \multirow{2}{*}{$\begin{array}{c}\text { AUC } \\
0.86\end{array}$} & \multirow{2}{*}{$\begin{array}{c}\text { No. } \\
71\end{array}$} & \multirow{2}{*}{$\begin{array}{c}\text { Gene Name } \\
\text { TRPM3 }\end{array}$} & \multirow{2}{*}{$\begin{array}{c}t \text { Test Nevi vs. } \\
\text { Melanoma }\end{array}$} & \multicolumn{2}{|c|}{$\begin{array}{c}\text { Ratio Melanoma } \\
\text { vs. Nevi }\end{array}$} & \multirow{2}{*}{$\begin{array}{r}\text { AUC } \\
0.72\end{array}$} \\
\hline & & & 0.456 & $\nabla$ & & & & & 0.762 & $\nabla$ & \\
\hline 26 & $A Q P 3$ & $6.9 \times 10^{-7}$ & 0.067 & $\nabla$ & 0.97 & 72 & CHRNA10 & $1.5 \times 10^{-2}$ & 0.759 & $\nabla$ & 0.68 \\
\hline 27 & KCNN4 & $1.5 \times 10^{-6}$ & 3.79 & 4 & 0.93 & 73 & $A Q P 9$ & $1.9 \times 10^{-2}$ & 0.56 & $\nabla$ & 0.75 \\
\hline 28 & SCN1B & $1.5 \times 10^{-6}$ & 0.657 & $\nabla$ & 0.83 & 74 & $V D A C 3$ & $1.9 \times 10^{-2}$ & 1.27 & 4 & 0.78 \\
\hline 29 & $L R R C 8 E$ & $1.5 \times 10^{-6}$ & 0.563 & $\nabla$ & 0.82 & 75 & KCNV1 & $2.0 \times 10^{-2}$ & 1.737 & 4 & 0.70 \\
\hline 30 & CACNB1 & $2.9 \times 10^{-6}$ & 0.614 & $\nabla$ & 0.82 & 76 & $V D A C 2$ & $2.0 \times 10^{-2}$ & 1.15 & 4 & 0.71 \\
\hline 31 & KCNJ12 & $3.5 \times 10^{-6}$ & 0.388 & $\nabla$ & 0.80 & 77 & CHRNB1 & $2.1 \times 10^{-2}$ & 0.754 & $\nabla$ & 0.68 \\
\hline 32 & KCNJ18 & $3.5 \times 10^{-6}$ & 0.388 & $\nabla$ & 0.80 & 78 & ANO2 & $2.4 \times 10^{-2}$ & 0.67 & $\nabla$ & 0.68 \\
\hline 33 & TRPM4 & $3.6 \times 10^{-6}$ & 0.154 & $\nabla$ & 0.87 & 79 & CHRNB2 & $2.6 \times 10^{-2}$ & 1.383 & 4 & 0.70 \\
\hline 34 & KCNS3 & $7.7 \times 10^{-6}$ & 0.403 & $\nabla$ & 0.93 & 80 & SCNN1G & $2.8 \times 10^{-2}$ & 1.45 & 4 & 0.67 \\
\hline 35 & PKD2L1 & $8.7 \times 10^{-6}$ & 2.66 & 4 & 0.86 & 81 & TRPC6 & $2.8 \times 10^{-2}$ & 0.594 & $\nabla$ & 0.67 \\
\hline 36 & $P 2 R X 4$ & $1.0 \times 10^{-5}$ & 1.756 & 4 & 0.85 & 82 & KCNA1 & $3.0 \times 10^{-2}$ & 0.79 & $\nabla$ & 0.67 \\
\hline 37 & GRIK2 & $3.9 \times 10^{-5}$ & 3.922 & 4 & 0.86 & 83 & PKD2L2 & $3.0 \times 10^{-2}$ & 0.447 & $\nabla$ & 0.52 \\
\hline 38 & KCNJ4 & $5.0 \times 10^{-5}$ & 2.87 & 4 & 0.84 & 84 & GABRA6 & $3.9 \times 10^{-2}$ & 0.622 & $\nabla$ & 0.65 \\
\hline 39 & TRPM2 & $6.5 \times 10^{-5}$ & 0.219 & $\nabla$ & 0.93 & 85 & GRINB2 & $3.9 \times 10^{-2}$ & 1.225 & 4 & 0.67 \\
\hline 40 & CLCN7 & $1.2 \times 10^{-4}$ & 1.753 & 4 & 0.80 & 86 & KCNJ2 & $4.0 \times 10^{-2}$ & 1.33 & 4 & 0.72 \\
\hline 41 & MCOLN3 & $2.2 \times 10^{-4}$ & 0.352 & $\nabla$ & 0.62 & 87 & TRPV5 & $4.0 \times 10^{-2}$ & 1.29 & 4 & 0.66 \\
\hline 42 & $S C N 2 B$ & $2.6 \times 10^{-4}$ & 0.483 & $\nabla$ & 0.71 & 88 & ASIC1 & $4.1 \times 10^{-2}$ & 0.71 & $\nabla$ & 0.63 \\
\hline 43 & LRRC $8 D$ & $2.8 \times 10^{-4}$ & 1.39 & 4 & 0.78 & 89 & $A Q P 5$ & $4.1 \times 10^{-2}$ & 1.498 & 4 & 0.67 \\
\hline 44 & MCOLN1 & $3.8 \times 10^{-4}$ & 1.43 & 4 & 0.72 & 90 & CACNG3 & $4.3 \times 10^{-2}$ & 1.903 & 4 & 0.73 \\
\hline 45 & CLCN6 & $5.0 \times 10^{-4}$ & 0.74 & $\boldsymbol{\nabla}$ & 0.79 & 91 & TRPC4 & $4.3 \times 10^{-2}$ & 2.097 & 4 & 0.69 \\
\hline 46 & CNGA1 & $5.0 \times 10^{-4}$ & 0.58 & $\nabla$ & 0.72 & & & & & & \\
\hline
\end{tabular}


Table 3. Ion channels genes showing very high discriminating ability (AUC > 0.90) in the Talantov dataset were validated in a first round validation in the Raskin dataset. Genes passing the first validation were then validated in the Riker dataset. Genes passing screening phase and all two validations were searched in Pubmed to identify those never directly related to melanoma. Genes showing 0 value in the "Novelty" column are genes never related to melanoma according to Pubmed abstract. Five genes were selected according to this procedure (SCNN1A, GJB3, KCNK7, GJB1, KCNN2). Empty cells indicate lack of validation.

\begin{tabular}{|c|c|c|c|c|c|c|c|c|}
\hline \multirow{3}{*}{ No. } & \multirow{3}{*}{ Gene Name } & \multicolumn{3}{|c|}{$\begin{array}{l}\text { Screening Phase (in the Talantov Dataset, } \\
\text { GEO, GDS1375) }\end{array}$} & \multirow{3}{*}{$\begin{array}{c}\begin{array}{c}\text { First-Round Validation } \\
\text { (in the Raskin Dataset, } \\
\text { GEO GSE15605) * }\end{array} \\
62 \text { Patients } \\
\begin{array}{c}\text { Validation on AUC } \\
\text { Value * }\end{array}\end{array}$} & \multirow{3}{*}{$\begin{array}{c}\text { Second-Round } \\
\text { Validation (in the Riker } \\
\text { Dataset, Oncomine) } \\
59 \text { Patients } \\
\begin{array}{c}\text { Validation on Ratio } \\
\text { Value }\end{array} \\
\end{array}$} & \multirow{3}{*}{$\begin{array}{c}\begin{array}{c}\text { Novelty (in PubMeds } \\
\text { Abstracts) }\end{array} \\
\\
\text { Gene Name and } \\
\text { Melanoma Words } \\
\text { Co-Occurrence }\end{array}$} & \multirow[t]{3}{*}{$\begin{array}{l}\text { Full in Silico } \\
\text { Validation }\end{array}$} \\
\hline & & \multicolumn{3}{|c|}{63 Patients } & & & & \\
\hline & & $\begin{array}{c}t \text { Test } \\
\text { Melanoma vs. Nevi }\end{array}$ & $\begin{array}{l}\text { Ratio Melan. } \\
\text { vs. Nevi }\end{array}$ & AUC & & & & \\
\hline 1 & SCNN1A & $1.0 \times 10^{-14}$ & 0.07 & 0.98 & Yes (0.85) & Yes $(-4.94)$ & 0 & $\longleftarrow$ \\
\hline 2 & ANO1 & $8.6 \times 10^{-18}$ & 0.231 & 0.98 & Yes $(0.87)$ & & & \\
\hline 3 & GJA1 & $2.1 \times 10^{-9}$ & 0.086 & 0.98 & Yes $(0.88)$ & & & \\
\hline 4 & GJB5 & $3.4 \times 10^{-13}$ & 0.1277 & 0.97 & & & & \\
\hline 5 & GJB3 & $2.1 \times 10^{-10}$ & 0.2453 & 0.96 & Yes $(0.86)$ & Yes $(-6.662)$ & 0 & $\longleftarrow$ \\
\hline 6 & $A Q P 3$ & $6.9 \times 10^{-7}$ & 0.067 & 0.97 & & & & \\
\hline 7 & SCNN1B & $1.4 \times 10^{-14}$ & 0.313 & 0.96 & Yes $(0.87)$ & & & \\
\hline 8 & VDAC1 & $2.0 \times 10^{-10}$ & 1.8 & 0.96 & & & & \\
\hline 9 & CLIC1 & $1.9 \times 10^{-12}$ & 1.738 & 0.96 & & & & \\
\hline 10 & GABRE & $2.3 \times 10^{-13}$ & 0.203 & 0.95 & Yes $(0.88)$ & Yes $(-3.162)$ & $\geq 1$ & \\
\hline 11 & KCNK7 & $1.8 \times 10^{-17}$ & 0.081 & 0.94 & Yes $(0.86)$ & Yes $(-2.832)$ & 0 & $\longleftarrow$ \\
\hline 12 & KCND3 & $2.0 \times 10^{-11}$ & 0.487 & 0.94 & Yes $(0.89)$ & & & \\
\hline 14 & KCNN4 & $1.5 \times 10^{-6}$ & 3.79 & 0.93 & & & & \\
\hline 13 & ITPR3 & $1.1 \times 10^{-9}$ & 2.311 & 0.93 & & & & \\
\hline 15 & KCNK1 & $8.6 \times 10^{-11}$ & 0.269 & 0.93 & Yes (0.89) & & & \\
\hline 16 & KCNS3 & $7.7 \times 10^{-6}$ & 0.403 & 0.93 & & & & \\
\hline 17 & TRPM2 & $6.5 \times 10^{-5}$ & 0.219 & 0.93 & & & & \\
\hline 18 & GRIA1 & $8.7 \times 10^{-11}$ & 0.1049 & 0.93 & & & & \\
\hline 19 & GJB1 & $3.4 \times 10^{-8}$ & 2.643 & 0.93 & Yes $(0.87)$ & Yes (3.303) & 0 & \\
\hline 20 & KCNN2 & $3.6 \times 10^{-10}$ & 4.337 & 0.91 & Yes (0.91) & Yes (2.284) & 0 & \\
\hline
\end{tabular}

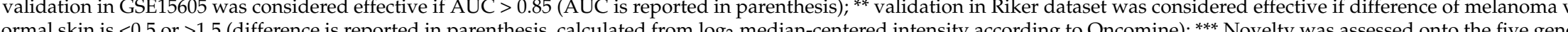
validated in the first and second validations steps. 

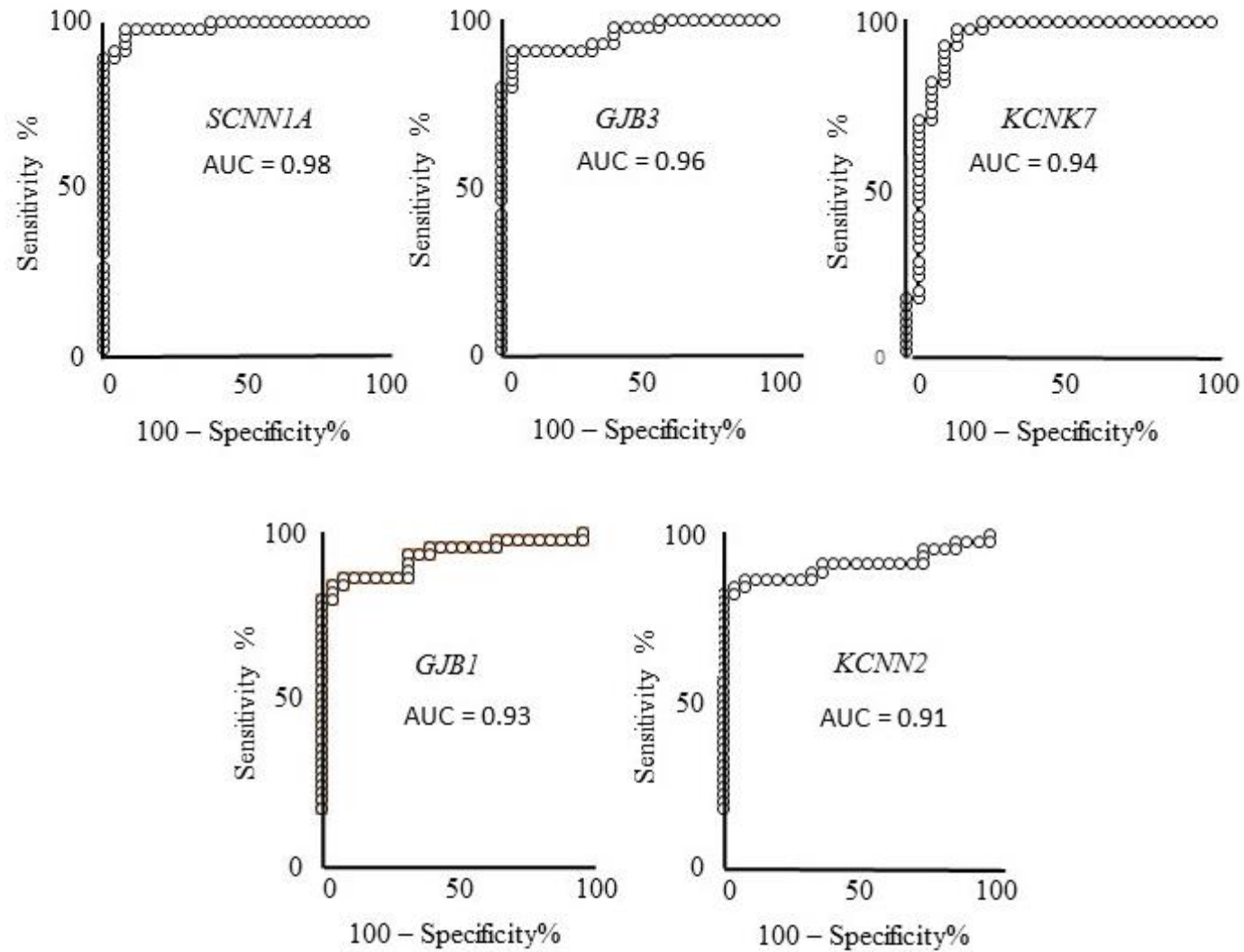

Figure 2. ROC analysis of the five genes expression showing a very high ability to discriminate controls from melanoma samples, validated in two samples datasets. These genes also show a strong expression ratio in the third dataset and are not reported to be related to melanoma according to PubMed searches. ROC analysis evaluates how the given measure (gene-expression level in this case) relates to sensitivity (ability to detect melanoma presence) and specificity (ability to detect melanoma absence). AUC (area under curve) of SCNN1A, GJB3, KCNK7, GJB1, and KCNN2 indicate very high ability of their expression levels to discriminate melanoma from controls, namely $98 \%, 96 \%, 94 \%, 93 \%$, and $91 \%$, respectively.

\subsection{Experimental Validation}

According to the in silico screening and validations steps carried out and described above, SCNN1A, GJB3, KCNK7, GJB1, KCNN2 genes were selected as best candidate melanoma markers and potential molecular targets. The five identified genes are down-regulated in three cases (namely SCNN1A, GJB3, KCNK7) and up-regulated in two cases (namely GJB1 and KCNN2). Interestingly, both down- and up-regulated molecules may represent suitable molecular targets, exploiting the available blockers or activators, respectively. The five genes were then analyzed as targets of known FDA-approved drugs. The analysis was carried out on http:/ / www.dgidb.org/search_interactions. Table 4 reports the results of this analysis, indicating a number of drugs (namely triamterene, amiloride, flufenamic acid, carbenoxolone, miconazole, tubucurarine, and bendroflumethiazide) known to target the identified ion channels. Main known tissue targets and pharmacological actions are also reported; such drugs act on muscles, joints, kidney, CNS, and also act on systemic targets. We focused our attention onto miconazole, an antifungal compound commonly used to treat skin infections. Miconazole has known skin distribution and dermatological pharmacokinetics; we, therefore, hypothesized it may be suitable for other skin diseases.

A Chilibot analysis identifies literature-reported functional relationships within user-defined terms. It identified the known functional relationships reported in literature among melanoma, ion channels, miconazole and cytochrome P450, one of the best characterized targets of miconazole. Chilibot analysis is reported in Figure 3, highlighting that miconazole inhibits cytochrome P450; 
melanoma and cytochrome P450 are connected by both stimulatory and inhibitory relations; potassium channels are known to inhibit cytochrome P450 [28] and their inhibitors are known to inhibit melanoma [29]. According to this scenario, a potassium channel inhibitor and cytochrome P450 inhibitor such as miconazole may significantly affect melanoma proliferation. Miconazole was then tested in vitro in a proliferation assay on two human melanoma cell lines, i.e., one more aggressive (namely A-375) and the other less aggressive (namely SKMEL-28). Proliferation was measured in the presence of $10 \%$ FCS. The results of a dose-dependent and time-dependent proliferation assay are reported in Figure 4A,B. Miconazole 10, 30, and $50 \mu \mathrm{M}$ doses show a strong dose-dependent inhibition of serum-induced proliferation. Figure $4 \mathrm{C}$ shows that miconazole does not have any inhibitory effect on keratinocytes ad fibroblast control cells. Figure 5 reports the number of dead cells in the presence of $10 \%$ serum, indicating 30 and $50 \mu \mathrm{M}$ as more potent cell-death inducers both in A-375 and in SKMEL-28 cells.

We, therefore, investigated whether the anti-proliferation effect of miconazole may be affected by specifically modulating KCNN2 expression. Figure 6 reports the strong increase of miconazole anti-proliferation effect upon KCNN2 siRNA silencing (Figure 6A). Western blot analysis and densitometry quantification is reported in Figure $6 \mathrm{~B}$ and confirms the strong downregulation of KCNN2 achieved by siRNA treatment. Since the molecular form of miconazole used in the present study is miconazole-nitrate, as control the effect of ammonium-nitrate was also evaluated. Figure $6 \mathrm{C}$ shows that nitrate, at the same doses used for miconazole, does not show any significant effect.

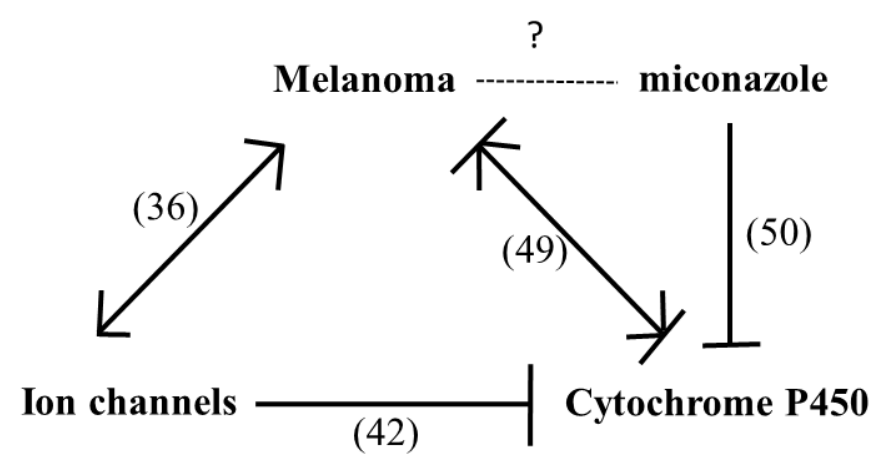

Figure 3. Chilibot analysis of Pubmed reported interactive relationships. According to the linguistic analysis carried out by Chilibot, miconazole is known to inhibit cytochrome P450; melanoma and cytochrome P450 are connected by both stimulatory and inhibitory relations; ion channels inhibit cytochrome P450 and stimulate melanoma. In parenthesis indicate number of abstracts found in PubMed is reported. 
Table 4. Gene-drug interaction according to the Drug Gene Interaction Database (www.dgidb.org). The five genes selected in Table 3 are investigated. Drugs known to target the given genes and interaction type are according to www.dgidb.org. Main target tissues, pharmacological action and IUPAC (International Union of Pure and Applied Chemistry) are derived from Drugbank (https://www.drugbank.ca/drugs). EC50 of the indicated pharmacological actions are also reported with corresponding reference. References indicating the ion channel/drug interaction are reported.

\begin{tabular}{|c|c|c|c|c|c|c|}
\hline Gene Name & $\begin{array}{l}\text { Drug Targeting the Gene, According to } \\
\text { www.dgidb.org, and IUPAC Name }\end{array}$ & Reference (PMID) & $\begin{array}{l}\text { Interaction Type } \\
\text { with the Gene }\end{array}$ & Main Target Tissue & Action and Indications & EC50 \\
\hline \multirow[b]{2}{*}{ SCNN1A } & $\begin{array}{c}\text { Triamterene } \\
\text { 6-phenylpteridine-2,4,7-triamine }\end{array}$ & [30] & channel blocker & kidney & diuretic, anti-edema & $1660 \mathrm{nM}[31]$ \\
\hline & $\begin{array}{c}\text { Amiloride } \\
\text { 3,5-diamino-6-chloro-N- } \\
\text { (diaminomethylidene)pyrazine-2-carboxamide }\end{array}$ & [32] & channel blocker & kidney & $\begin{array}{l}\text { diuretic; congestive heart } \\
\text { failure; hypertension. }\end{array}$ & $0.1 \mu \mathrm{M}[33]$ \\
\hline \multirow[b]{2}{*}{ GJB3 } & $\begin{array}{c}\text { Flufenamic acid } \\
2-\{[3-\text { (trifluoromethyl)phenyl]amino\}benzoic acid }\end{array}$ & [34] & inhibitor & muscles joints & anti-cancer & $100 / 200 \mu \mathrm{M}[35]$ \\
\hline & $\begin{array}{c}\text { Carbenoxolone } \\
\text { 2S,4aS,6aR,6aS,6bR,8aR,10S,12aS,14bR)-10- } \\
\text { (3-carboxypropanoyloxy)-2,4a,6a,6b,9,9,12a- } \\
\text { heptamethyl-13-oxo-3,4,5,6,6a,7,8,8a,10,11,12,14b- } \\
\text { dodecahydro-1H-picene-2-carboxylic acid }\end{array}$ & {$[34,36]$} & inhibitor & digestive tract & anti-ulcer/neuro protection & $48 \mu \mathrm{M}[37]$ \\
\hline KCNK7 & Not found & & & & & \\
\hline GJB1 & Not found & & & & & \\
\hline \multirow{3}{*}{ KCNN2 } & $\begin{array}{c}\text { Miconazole } \\
\text { 1-[2-(2,4-dichlorophenyl)-2-[(2,4-dichlorophenyl) } \\
\text { methoxy]ethyl]-1H-imidazole }\end{array}$ & [38] & Inhibitor & systemic, skin & anti-fungal infections & $75 \mu \mathrm{M}[39]$ \\
\hline & $\begin{array}{c}\text { Tubocurarine } \\
\text { (1S,16R)-9,21-dihydroxy-10,25-dimethoxy-15,15,30- } \\
\text { trimethyl-7,23-dioxa-15,30-diazaheptacyclo } \\
{\left[22.6 .2 .2^{3,}, .1^{8}, 12.18,22.0^{27}, 31.0^{16}, 34\right.} \\
3,5,8(34), 9,11,18(33), 19,21,24 \\
26,31,35 \text {-dodecaen-15-ium } \\
\end{array}$ & [34] & channel blocker & CNS & $\begin{array}{l}\text { diagnostic in myastenia } \\
\text { gravis; to treat smoking } \\
\text { withdrawl syndrom }\end{array}$ & $1.3 \mu \mathrm{M}[40]$ \\
\hline & $\begin{array}{c}\text { Bendroflumethiazide } \\
\text { 3-benzyl-1,1-dioxo-6-(trifluoromethyl)-3,4-dihydro- } \\
\text { 2H-1 } \lambda^{6}, 2,4 \text {-benzothiadiazine-7-sulfonamide }\end{array}$ & [34] & channel blocker & $\begin{array}{l}\text { kidney smooth } \\
\text { muscle cells }\end{array}$ & $\begin{array}{l}\text { Anti HBV, diuretic; } \\
\text { anti-edema; hypertension }\end{array}$ & $53 \mu \mathrm{M}[41]$ \\
\hline
\end{tabular}




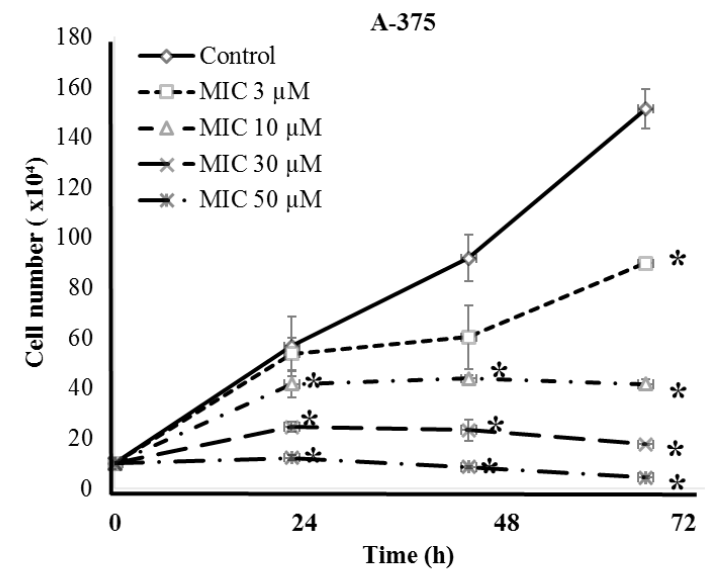

B

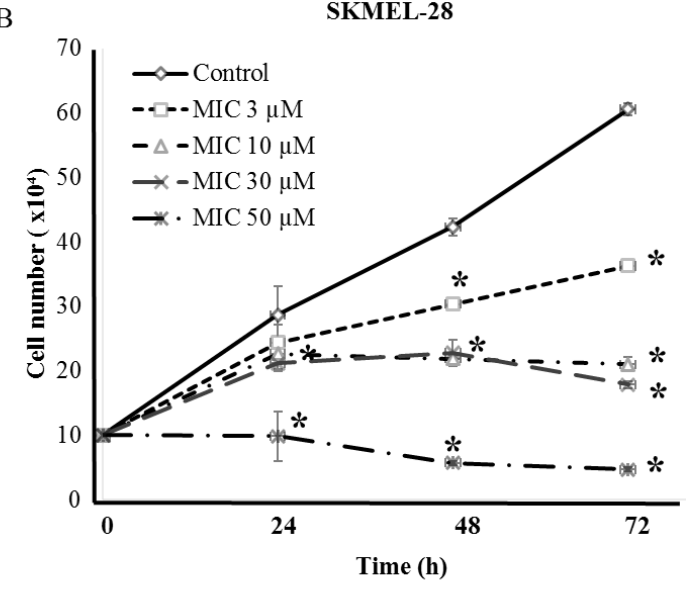

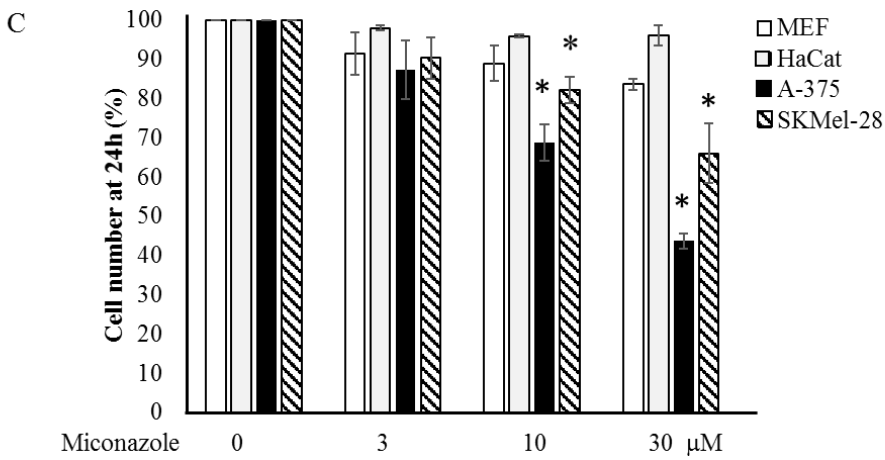

Figure 4. (A,B) Proliferation of A-375 (A) and SKMEL-28 (B) melanoma cells under miconazole treatment. ${ }^{*}$ indicates $p<0.01$; Miconazole strongly inhibits the growth of either melanoma cell lines in a dose-dependent manner; and (C) miconazole does not affect proliferation of control cells (HaCat keratinocytes and embryonic fibroblasts).

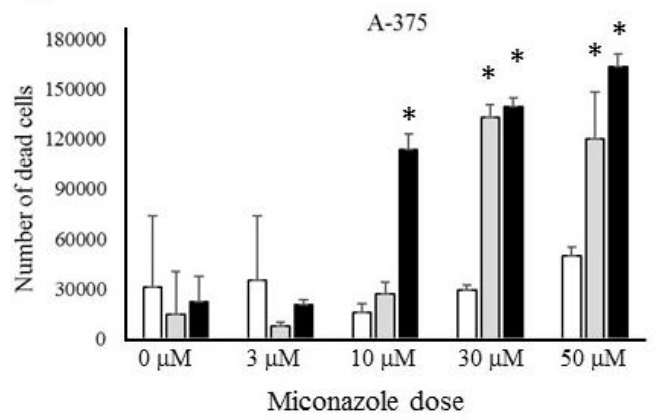

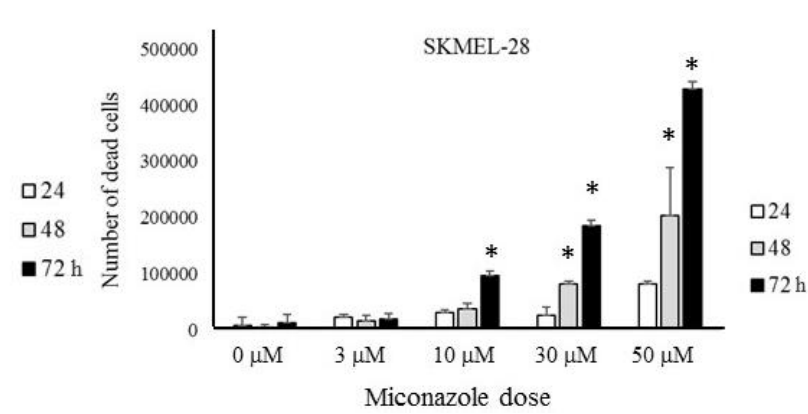

Figure 5. Quantification of cell death as function of miconazole dose and time of treatment, (A) A-375 (B) SKMEL-28. * indicates $p<0.01$. 


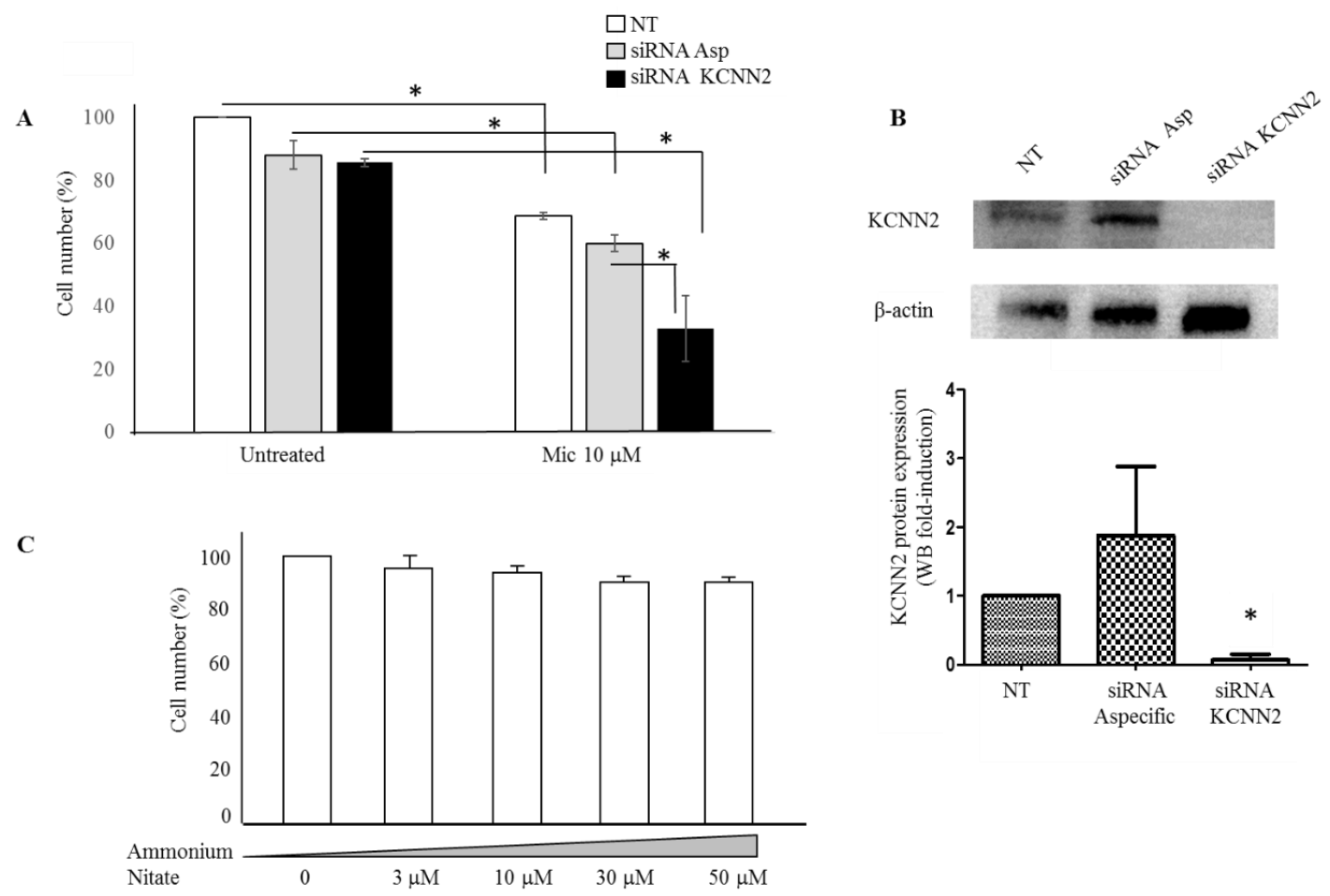

Figure 6. A-375 cells under KCNN2-siRNA and ammonium nitrate treatment. (A) Miconazole effect in A-375 cells transfected with siRNA-KCNN2 and non-specific siRNA control. Bars without miconazole (left end of the graph) are expressed as \% of untreated cells (NT); bars with miconazole (right end of the graph) are expressed as \% of the corresponding control (NT with miconazole vs. NT without miconazole; siRNA Asp with miconazole vs. siRNA Asp without miconazole; siRNA KCNN2 with miconazole vs. siRNA KCNN2 without miconazole). Miconazole anti-proliferative effect is almost doubled in siRNA KCNN2-treated cells as compared to siRNA non-specific-treated cells. (B) KCNN2 protein expression in siRNA treated cells. siRNA KCNN2 strongly reduces KCNN2 expression in A-375 cells. (C) Ammonium nitrate has no anti-proliferative effect on A-375 cells; therefore, we may conclude that the anti-proliferative action of miconazole-nitrate is due to miconazole. ${ }^{*}$ indicate $p<0.01$.

\subsection{Mechanisms Underlying Miconazole Action}

Miconazole is reported to primarily target $14-\alpha$ demethylase, a cytochrome P-450 enzyme involved in conversion of lanosterol to ergosterol, an essential component of the fungal cell membrane (see Drug Bank at https:/ /www.drugbank.ca/drugs/DB01110). Nevertheless, it also inhibits several other targets, including endothelial nitric oxide synthase and inducible nitric oxide synthase as well as several potassium channels, namely: calcium-activated potassium channel subunit alpha-1, calcium-activated potassium channel subunit beta-1, calcium-activated potassium channel subunit beta-2, calcium-activated potassium channel subunit beta-3, calcium-activated potassium channel subunit beta- 4 , intermediate conductance calcium-activated potassium channel protein 4 , small conductance calcium-activated potassium channel protein 1 , small conductance calcium-activated potassium channel protein 2, small conductance calcium-activated potassium channel protein 3 , potassium voltage-gated channel subfamily $\mathrm{H}$ member 2 , potassium voltage-gated channel subfamily $\mathrm{H}$ member 6, and potassium voltage-gated channel subfamily $\mathrm{H}$ member 7 . It is also a partial agonist of nuclear receptor subfamily 1 group I member 2. According to a STRING analysis carried out at www.string-db.org, such proteins are strongly involved in arginine metabolism, potassium transport, control of guanylate cyclase, nitric oxide synthesis, blood circulation and synaptic transmission. Table 5 highlights the top 10 biological processes enriched in a statistically significant way by analyzing the above reported proteins, known miconazole targets. 
Table 5. Top 10 biological processes enriched in a statistically significant way by investigating in a STRING "multiple proteins" search the following molecules: CYP51A1, NOS3, NOS2, NOS1, KCNMA1, KCNMB3, KCNN4, KCNH2, KCNH7, KCNH6, KCNN2.

\begin{tabular}{llc}
\hline \multicolumn{1}{c}{ Biological Process } & Pathway ID & False Discovery Rate \\
\hline Potassium ion transmembrane transport & GO:00781805 & $1.9 \times 10^{-7}$ \\
Arginine catabolic process & GO:0006527 & $6.4 \times 10^{-6}$ \\
Synaptic transmission & GO:0007268 & $6.4 \times 10^{-6}$ \\
Positive regulation of guanylate cyclase activity & GO:0031284 & $4.2 \times 10^{-5}$ \\
Regulation of system process & CO:0044057 & $4.2 \times 10^{-5}$ \\
Nitric oxide biosynthetic process & GO:0006809 & $5.3 \times 10^{-5}$ \\
Regulation of potassium ion transport & GO:0043266 & $5.7 \times 10^{-5}$ \\
Regulation of blood circulation & GO:1903522 & $5.7 \times 10^{-5}$ \\
Nitric oxide mediated signal transduction & GO:0007263 & $8.1 \times 10^{-5}$ \\
Blood circulation & GO:0008015 & $8.3 \times 10^{-5}$ \\
\hline
\end{tabular}

\section{Discussion}

Ion channels have been shown to play a role in melanoma biology [42]. The number of studies relating ion channels to melanoma has increased in the last few years and ion channels are now recognized as potential co-targets in the new melanoma therapeutic strategies currently under continuous development [43]. We have previously reported strong and significant expression changes of several ion channels in solid tumors including glioblastoma, breast cancer, lung cancer, bladder cancer, and melanoma [19] and also proposed a possible role of ion channels in brain metastases onset [44]. Figure 3 of the present study also underlines that several studies identify reciprocal stimulatory relationships of melanoma and ion channels. The present study presents for the first time an extensive analysis of ion channels expression in human melanoma biopsies indicating a number of potential highly effective markers accurately validated in silico and never previously related to melanoma. An in silico procedure (summarized in Figure 1), after an initial screening on a first human biopsies dataset, progressively leads to the selection of five genes in a double-validation step carried out in two more human melanoma-patients datasets. The five ion channels selected as best candidates and never previously directly related to melanoma (namely SCNN1A, GJB3, KCNK7, GJB1, KCNN2) show very high AUC values ( $>0.90$ in all cases) and very high specificity and sensitivity values $(>90 \%$ in most cases). In a few cases these genes have been related to other cancers such as lung cancer [45], breast cancer [46], thyroid cancer [47], and ovarian cancer [48]. On the other hand, mir125B, which is known to target the SCNN1A gene [49] has been reported to control melanoma progression [50].

We have previously published a study involving a pure in silico four-step validation procedure carried out on autophagy-related genes in more than 500 melanoma patients [51]. In that study we demonstrated that many autophagy-related genes undergo relevant and significant expression changes in melanoma biopsies as compared to controls, and three genes, namely WIP1, PEX3 and $B A G 1$, show impressive melanoma markers features, such as very high AUC values and sensibility and specificity values. Interestingly enough, ion channels recently emerged as key regulators of autophagy [52], further extending their potential clinical applications. We, therefore, underline here that ion channels may represent suitable molecular targets for novel therapeutic/diagnostic approaches in the melanoma field. The current study investigates this hypothesis. By analyzing ion channels expression in 170 human melanoma biopsies, we show that an accurate preliminary in silico validation is able to identify candidates as relevant markers or molecular targets (see Table 3). A number of drugs, commonly used in clinics in different pathological conditions, are known to target the 5 best candidates identified. This allowed us to hypothesize novel potential clinical applications in a melanoma set up, for the drugs indicated in Table 3, within a drug repositioning strategy. Although all drugs listed in Table 4 may be potentially effective, we focused our attention on miconazole, given its known skin-targeting properties [53]. Miconazole is a known cytochrome P-450 inhibitor targeting ion channels including KCNN2 [38,54]. In the clinical practice it is commonly used as an antifungal topic compound in skin infections or for systemic infections, and, within the drugs reported 
in Table 3, sounds as the best candidate for skin-related lesions or systemic lesions of skin origin such as melanoma. Further, miconazole targets the KCNN2 gene; this gene appears to be the best candidate among the five identified in Table 3, being the only one with AUC $>0.90$ in both screening phase and first validation phase, and with very high melanoma vs. ctrl expression ratios (see Table 3 ). Figure 4 of the present study demonstrates that miconazole strongly reduces (up to $90 \%$ ) the serum-induced proliferation of A-375 (more-aggressive) and SKMEL-28 (less-aggressive) melanoma cells [55]. A375 and SK-MEL-28 cells are largely studied human melanoma cells for their different aggressiveness and malignancy. We have recently correlated their aggressive phenotype with different molecular profiles [56]. In both cell types high levels of p53 have been demonstrated [57], while A-375 express higher Bax level [58]. Figure 4 also shows that the anti-proliferation effect of miconazole appears to be specific for melanoma cells, since proliferation of ctrl cells (keratinocytes and fibroblasts) is not affected. All together such data suggest a possible topical application of miconazole in the skin treatment of the excised primary melanoma.

Figure 5 shows that miconazole also induces a strong cell-death, possibly suggesting adjuvant applications in metastatic stages. Miconazole has been previously shown to have some anti-proliferative effect in mouse melanoma cells (about 50\% inhibitory action) and a mild anti-melanogenesis effect [59], while we show for the first time a much stronger activity both as anti-proliferation and as cell-death inducer in human cells lines, particularly in A-375 cells, known to have an aggressive phenotype. Antitumor effects of miconazole have been previously reported in cancers setup different than melanoma [60-63], while the present study represents the first evidence indicating miconazole strong anti-proliferative and death-inducing activity in melanoma cells. Interestingly, we demonstrate in the present study that the KCNN2 ion channel strongly modulates miconazole anti-melanoma effect. In fact, in A375 cells, specific silencing by siRNA-KCNN2 leads to a strong increase of miconazole anti-proliferative effect.

Interestingly, miconazole, while known as a relevant antifungal drug, is also known to recognizes eukaryotic targets including several potassium channels. It has shown to induce cytoprotective effect under hypoxia conditions, likely by inhibiting HMGB1 and IL-8 release in Caco-2 intestinal cells [64]. Further, it has been shown to induce post-ischemic neurogenesis in rats [65], immune response in fish [66], to have promising anti Alzheimer's disease activity [67] and to interact with the anticoagulant drug warfarin [68]. Further investigation on the underlying mechanism are currently under investigation. In agreement with findings of the present study, other antifungal compounds, namely itraconazole, show potent anti-melanoma action in vivo and in vitro on A-375 and SKMEL-28 cells, down-regulating different pathways including PI3K/mTOR [69]. Noteworthy, increased melanogenesis is a frequent sing in fungal infections [70], fungal infections in some cases mimicking melanoma lesions [71]. Accordingly, previous studies report anti-melanogenesis action of antifungal compounds such as clotrimazole by interfering on ERK and PI3K/AKT activity [72]. Table 5 underlines that the known targets of miconazole are primarily involved in potassium transport, arginine catabolism as well as guanylate cyclase activity and nitric oxide synthesis.

In conclusion all together these evidences support the role of ion channels in the melanoma setup and future investigation on anti-melanoma effect in vivo of miconazole and other anti-fungal compounds.

\section{Materials and Methods}

Ion channels investigated in the current study were taken from the list according to HUGO Gene Nomenclature Committee (HGNC), European Bioinformatics Institute (EMBL-EBI) at https://www.genenames.org/data/genegroup/\#!/group/177. The ion channels list includes 328 genes and is reported in Table 1 in alphabetic order. The general procedure followed in the present study is depicted in Figure 1. It consists of a preliminary in silico phase (screening phase, first-round and second-round validation steps, and novelty assessment) and of a following experimental validation of one of the identified molecular targets in proliferation/cell-death assays. 
In silico steps: screening phase and two validation steps. The screening and the two validation steps were carried out onto a total of 170 patients (63 in the screening phase +62 in the first round validation +45 in the third round validation).

Selection step: in silico selection of suitable melanoma markers. Expression of the 328 ion channels genes reported in Table 1 was investigated in a collection of human melanoma biopsies and controls. Namely, the melanoma GDS1375 dataset [73] (Talantov et al, 2005) from the GEO database (https://www.ncbi.nlm.nih.gov/gds/) was chosen, containing expression data from 63 samples (45 melanoma-patients and 18 nevi-patients) with free data download. The significance of the differential expression was evaluated according to Student $t$ test analysis and fold change. ROC analysis, the well accepted test for binary assessments [74], was then performed to measure how effective is the expression-level of any given gene to discriminate healthy-from melanoma-biopsies. The computed area under curve (AUC) value ranges from 0.5 to 1 , indicating a minimum of $50 \%$ to a maximum of $100 \%$ discrimination ability. Other datasets in the GEO database are available, such as GDS1989 and GDS1965, but with only few samples. The GDS1375 dataset used in this selection step and the GSE15605 dataset used in the following first validation step, were chosen due to the large number of melanoma biopsies and control biopsies. Transcriptomic data are from Affymetrix Human Genome U133A Array and from Affymetrix Human Genome U133 Plus 2.0 Array platforms, respectively.

In silico first validation step: validation of identified genes was carried out on a different GEO dataset, namely GSE15605 [75] containing expression data form 62 patients-biopsies (namely 16 controls, 46 primary melanoma and 12 metastatic melanoma samples). The 20 genes showing AUC $>0.90$ computed according to the GDS1375 dataset, were analyzed in the GSE15605 dataset and were considered validated if the computed AUC was $>0.85$. Under such condition, 11 genes were validated.

In silico second validation step: a further validation of the genes passing the screening and the first validation step was carried out in the Riker melanoma dataset [76] within the Oncomine database (www.oncomine.org). Such dataset contains 45 human samples (40 metastatic melanoma samples and five controls) and reports the expression values as $\log 2$-median centered intensity. This value was used to calculate the ratio of melanoma vs. normal skin groups. A ratio higher than 2 or lower than 0.5 was considered effective to validate. Seven genes passed the second validation step. Five of these seven genes (namely: SCNN1A, GJB3, KCNK7, GJB1, and KCNN2) show not-previously recognized relation with melanoma, according to a PubMed search carried out in September 2018, highlighting any co-occurrence of any gene-name and "melanoma" words in ALL fields. Therefore, these five genes were considered novel in silico validated melanoma markers and potential therapeutic targets.

\subsection{In Vitro Experimental Validation: Analysis of Potential "Druggability"}

Drugs potentially targeting the in silico validated genes SCNN1A, GJB3, KCNK7, GJB1, and KCNN2 were then investigated on the database available at http://www.dgidb.org/search_interactions. The analysis allows to identify FDA-approved drugs known to target the given genes.

\subsection{Chilibot Analysis}

Known functional interactions were investigated by Chilibot analysis (www.chilibot.net) [77]. Chilibot identifies literature-reported relationships within user-defined terms. This is achieved by looking at their co-existence in the same sentence within Pubmed abstracts. Such procedure identifies closer relations as compared to a plain Pubmed search. Chilibot then associates same-sentence co-occurrence to stimulatory- or inhibitory- or non-interactive relationships. A pairwise search was carried out indicating "melanoma", "ion channels", "miconazole" and "cytochrome P450" terms. The "advanced options" button was turned on, to account for all known synonyms of the given terms and minimize false negative findings (i.e., using all known synonyms in the search reduces the risk of ignoring abstracts containing synonyms of the given term) and the analysis was performed on the maximum number of abstracts possible (i.e., 50 abstracts). 


\subsection{Cell Culture and Melanoma Cells In Vitro Proliferation Assay}

Cells were used from the 3rd to 5th passages. SKMEL-28 and A-375 melanoma cells were from ATCC (Manassas, VA, USA) and were maintained in complete medium Dulbecco's modified Eagle's medium (DMEM; Hyclone, South Logan, UT, USA) and in complete medium Minimum Essential medium Eagle (MEM; Hyclone, South Logan, UT, USA) supplemented with 10\% FBS (Hyclone), 2 mM L-glutamine and $100 \mathrm{IU} / \mathrm{mL}$ penicillin/streptomycin (Invitrogen, Carlsbad, CA, USA) respectively in humidified $5 \% \mathrm{CO}_{2}$ atmosphere at $37^{\circ} \mathrm{C}$ as described $[78,79]$. Human keratinocytes (HaCat) and mouse embryonic fibroblasts (MEF cells) were from American Type Culture Collection (ATCC).

In some experiments, A-375 cells were treated with 3, 10, 30, and $50 \mu \mathrm{M}$ of ammonium nitrate (Merck, Darmstadt, Germany) as control of miconazole-nitrate, in $24 \mathrm{~h}$ proliferation assays.

The culture medium was changed every three days and when cells were sub-confluent; monolayers were harvested by 1 min exposure to $0.1 \%$ Trypsin-EDTA (Life Technologies Inc, Carlsbad, CA, USA).

Miconazole nitrate was from CliniSciences (Paris, France). SKMEL-28 and A-375 cells were plated at $10 \times 10^{5}$ and $8 \times 10^{4}$ respectively, in p35 plates dishes at time 0 . Then cells were starved for $18 \mathrm{~h}$ in serum-free medium and the next day treated with $3,10,30$, and $50 \mu \mathrm{M}$ of miconazole in complete fresh medium containing $10 \%$ FCS and DMSO at a final concentration of $50 \mu \mathrm{M}$. Control cells were treated with complete medium containing $10 \%$ FCS and DMSO at a final concentration of $50 \mu \mathrm{M}$. The effect of miconazole nitrate on cells proliferation in vitro was measured by directly counting the number of cells. At the end of incubation time (24, 48, and $72 \mathrm{~h}$ ), cells were harvested and number of live cells and dead cells was counted. Dead cells were quantified by trypan blue incorporation.

\subsection{KCNN2 Silencing by siRNA}

One day after plating $\left(4 \times 10^{4}\right.$ cells $\left./ \mathrm{mL}\right)$, A-375 cells were transfected with Lipofectamine 2000 (Invitrogen) plus $50 \mathrm{nM}$ small interfering RNA (siRNA) targeting KCNN2 gene (siRNA KCNN2) (Santa Cruz, CA, USA) or with the corresponding non-specific control siRNA (siRNA non-specific) (ThermoFisher, Waltham, MA, USA). After 5-h transfection, supernatant was discarded and fresh complete medium was added. The next day, KCNN2 expression in transfected cells was measured by Western blot analysis and miconazole treatment $(10 \mu \mathrm{M})$ was started. After $24 \mathrm{~h}$ of miconazole treatment, cell proliferation was measured.

\subsection{Western Blot Analysis}

Cells were washed with cold PBS and then cell lysates were prepared in cell lysis buffer (Cell Signaling, Denvers, MA, USA), 1\% sodium dodecylsulphate-polyacrylamide (SDS) (Sigma-Aldrich, St Louis, MO, USA) and $1 \mathrm{mM}$ phenylmethanesulfonyl fluoride solution (PMSF) (Sigma-Aldrich, St Louis, MO, USA). Protein concentration was measured by a bicinchoninic acid protein assay kit (Pierce, Rockford, IL, USA) according to manufacturer's instructions and then equal amounts of proteins $(25 \mu \mathrm{g})$ were subjected to sodium dodecylsulphate-polyacrylamide gel electrophoresis (SDS-PAGE) and transferred onto nitrocellulose membrane (GE Healthcare, Life science, Wien, Austria). Membranes were saturated with 5\% non-fat dry milk in T-TBS, incubated with the primary antibody overnight, and subsequently with horseradish peroxidase-conjugated (HRP) secondary antibody for $1 \mathrm{~h}$ at room temperature. Membranes were washed with T-TBS and developed using the chemiluminescence system (ECL Advance, Amersham Biosciences, San Diego, CA, USA). Antibody used: anti KCNN2/SK2 antibody was from Abcam (San Francisco, CA, USA); anti- $\beta$-actin was from Sigma (St Louis, MO, USA). Secondary antibody was HRP-goat anti-rabbit from Bio-Rad (Hercules, CA, USA). The intensity of Western blot bands was quantified by Bio-RAD Chemidoc Gel Imaging System with Image Lab 5.2.1. software (Bio-RAD, Hercules, CA, USA). 


\subsection{STRING Analysis}

STRING analysis at https:/ / string-db.org/ was performed to identify the biological processes most likely affected by the genes known to be miconazole targets. The "multiple proteins" search was carried out.

\subsection{Statistics}

Statistical significance was computed according to the Student's $t$-test; $p<0.05$ was chosen as significance threshold. ROC analysis was carried out with GraphPad Prism version 5 (GraphPad Software, San Diego, CA, USA, www.graphpad.com).

The sensitivity and specificity values were computed as previously reported [51] as the values corresponding to highest sensitivity-specificity product in each ROC curve data.

\section{Conclusions}

In conclusion, in the present study we show that many ion channels genes taken from the ion channels families (i.e., 91 out of 328 investigated genes) are differently expressed in melanoma vs. control human biopsies, according to an in silico analysis on 170 human samples. Five such genes (namely: SCNN1A, GJB3, KCNK7, GJB1, KCNN2) were identified as potential strong melanoma markers that had never been identified before. By in vitro experiments, one gene (namely: KCNN2) has been validated as a relevant molecular target in melanoma cell lines. Indeed, the antifungal drug miconazole shows an extremely high anti-proliferation activity in melanoma cell lines, mediated by KCNN2. We, therefore, conclude that ion channels are strongly involved in melanoma and that miconazole may exert a potent anti-melanoma activity.

Author Contributions: Conceptualization: D.D., C.G., P.M., F.F., and A.F.; formal analysis: D.D. and A.F.; funding acquisition: D.D., A.F., and P.M.; supervision: A.F.; validation: F.S.; visualization: F.S.; writing一original draft: D.D., F.F., and C.G.; writing - review and editing: F.F. and A.F.

Funding: The present study was supported in part by grants to D.D. and A.F. (RC2018, 3.4).

Conflicts of Interest: The authors declare no conflict of interest.

\section{References}

1. Bagal, S.K.; Brown, A.D.; Cox, P.J.; Omoto, K.; Owen, R.M.; Pryde, D.C.; Sidders, B.; Skerratt, S.E.; Stevens, E.B.; Storer, R.I.; et al. Ion channels as therapeutic targets: A drug discovery perspective. J. Med. Chem. 2013, 56, 593-624. [CrossRef] [PubMed]

2. Wickenden, A.; Priest, B.; Erdemli, G. Ion channel drug discovery: Challenges and future directions. Future Med. Chem. 2012, 4, 661-679. [CrossRef]

3. Weyer-Menkhoff, I.; Lötsch, J. Human pharmacological approaches to TRP-ion-channel-based analgesic drug development. Drug Discov. Today 2018, 23, 2003-2012. [CrossRef] [PubMed]

4. Ledwitch, K.V.; Roberts, A.G. Cardiovascular Ion Channel Inhibitor Drug-Drug Interactions with P-glycoprotein. AAPS J. 2017, 19, 409-420. [CrossRef] [PubMed]

5. Robertson, G.A. Endocytic control of ion channel density as a target for cardiovascular disease. J. Clin. Investig. 2009, 119, 2531-2534. [CrossRef]

6. Elliott, W.J.; Bistrika, E.A. Perindopril arginine and amlodipine besylate for hypertension: A safety evaluation. Expert Opin. Drug Saf. 2018, 17, 207-216. [CrossRef] [PubMed]

7. Kwai, N.C.G.; Arnold, R.; Wickremaarachchi, C.; Lin, C.S.-Y.; Poynten, A.M.; Kiernan, M.C.; Krishnan, A. V Effects of axonal ion channel dysfunction on quality of life in type 2 diabetes. Diabetes Care 2013, 36, 1272-1277. [CrossRef]

8. Pietschmann, T. Clinically Approved Ion Channel Inhibitors Close Gates for Hepatitis C Virus and Open Doors for Drug Repurposing in Infectious Viral Diseases. J. Virol. 2017, 91, e01914-16. [CrossRef]

9. Moorthy, N.S.H.N.; Poongavanam, V.; Pratheepa, V. Viral M2 ion channel protein: A promising target for anti-influenza drug discovery. Mini Rev. Med. Chem. 2014, 14, 819-830. 
10. Bhattacharya, A.; Biber, K. The microglial ATP-gated ion channel P2x7 as a CNS drug target. Glia 2016, 64, 1772-1787. [CrossRef] [PubMed]

11. Wei, F.; Yan, L.-M.; Su, T.; He, N.; Lin, Z.-J.; Wang, J.; Shi, Y.-W.; Yi, Y.-H.; Liao, W.-P. Ion Channel Genes and Epilepsy: Functional Alteration, Pathogenic Potential, and Mechanism of Epilepsy. Neurosci. Bull. 2017, 33, 455-477. [CrossRef] [PubMed]

12. Seefeld, M.A.; Lin, H.; Holenz, J.; Downie, D.; Donovan, B.; Fu, T.; Pasikanti, K.; Zhen, W.; Cato, M.; Chaudhary, K.W.; et al. Novel KV7 ion channel openers for the treatment of epilepsy and implications for detrusor tissue contraction. Bioorg. Med. Chem. Lett. 2018, 28, 3793-3797. [CrossRef]

13. Ullah, S.; Ali, N.; Khan, A.; Ali, S.; Nazish, H.R.; Uddin, Z. Epilepsy control with carbamazepine monotherapy from a genetic perspective. BMC Pharmacol. Toxicol. 2018, 19, 73. [CrossRef]

14. Mayor, S. Cystic fibrosis: Triple drug regimens that target defective ion channel improve lung function, studies show. BMJ 2018, 363, k4377. [CrossRef]

15. Sala, M.A.; Jain, M. Tezacaftor for the treatment of cystic fibrosis. Expert Rev. Respir. Med. 2018, 12, 725-732. [CrossRef] [PubMed]

16. Zhang, G.; Wang, X.; Xue, Q. Combined targeted ion channel therapy: Can it be an alternative choice for esophageal cancer patients? Med. Hypotheses 2018, 117, 59-62. [CrossRef]

17. Tuszynski, J.; Tilli, T.M.; Levin, M. Ion Channel and Neurotransmitter Modulators as Electroceutical Approaches to the Control of Cancer. Curr. Pharm. Des. 2017, 23, 4827-4841. [CrossRef]

18. Vancauwenberghe, E.; Noyer, L.; Derouiche, S.; Lemonnier, L.; Gosset, P.; Sadofsky, L.R.; Mariot, P.; Warnier, M.; Bokhobza, A.; Slomianny, C.; et al. Activation of mutated TRPA1 ion channel by resveratrol in human prostate cancer associated fibroblasts (CAF). Mol. Carcinog. 2017, 56, 1851-1867. [CrossRef]

19. Biasiotta, A.; D'Arcangelo, D.; Passarelli, F.; Nicodemi, E.M.; Facchiano, A. Ion channels expression and function are strongly modified in solid tumors and vascular malformations. J. Transl. Med. 2016, 14, 285. [CrossRef]

20. Ko, J.-H.; Ko, E.A.; Gu, W.; Lim, I.; Bang, H.; Zhou, T. Expression profiling of ion channel genes predicts clinical outcome in breast cancer. Mol. Cancer 2013, 12, 106. [CrossRef]

21. Li, H.; Ma, N.; Wang, J.; Wang, Y.; Yuan, C.; Wu, J.; Luo, M.; Yang, J.; Chen, J.; Shi, J.; et al. Nicotine Induces Progressive Properties of Lung Adenocarcinoma A549 Cells by Inhibiting Cystic Fibrosis Transmembrane Conductance Regulator (CFTR) Expression and Plasma Membrane Localization. Technol. Cancer Res. Treat. 2018, 17, 1533033818809984. [CrossRef] [PubMed]

22. Berrout, J.; Kyriakopoulou, E.; Moparthi, L.; Hogea, A.S.; Berrout, L.; Ivan, C.; Lorger, M.; Boyle, J.; Peers, C.; Muench, S.; et al. TRPA1-FGFR2 binding event is a regulatory oncogenic driver modulated by miRNA-142-3p. Nat. Commun. 2017, 8, 947. [CrossRef] [PubMed]

23. Xia, D.; Lai, D.V.; Wu, W.; Webb, Z.D.; Yang, Q.; Zhao, L.; Yu, Z.; Thorpe, J.E.; Disch, B.C.; Ihnat, M.A.; et al. Transition from androgenic to neurosteroidal action of $5 \alpha$-androstane- $3 \alpha, 17 \beta$-diol through the type A $\gamma$-aminobutyric acid receptor in prostate cancer progression. J. Steroid Biochem. Mol. Biol. 2018, 178, 89-98. [CrossRef] [PubMed]

24. Camacho, N.; Van Loo, P.; Edwards, S.; Kay, J.D.; Matthews, L.; Haase, K.; Clark, J.; Dennis, N.; Thomas, S.; Kremeyer, B.; et al. Appraising the relevance of DNA copy number loss and gain in prostate cancer using whole genome DNA sequence data. PLoS Genet. 2017, 13, e1007001. [CrossRef] [PubMed]

25. Sagredo, A.I.; Sagredo, E.A.; Cappelli, C.; Báez, P.; Andaur, R.E.; Blanco, C.; Tapia, J.C.; Echeverría, C.; Cerda, O.; Stutzin, A.; et al. TRPM4 regulates Akt/GSK3- $\beta$ activity and enhances $\beta$-catenin signaling and cell proliferation in prostate cancer cells. Mol. Oncol. 2018, 12, 151-165. [CrossRef] [PubMed]

26. Prickett, T.D.; Gartner, J.J.; Samuels, Y. Genetic and Functional Analysis of GRIN2A in Tumor Samples. Methods Mol. Biol. 2017, 1677, 93-116.

27. Leanza, L.; Romio, M.; Becker, K.A.; Azzolini, M.; Trentin, L.; Managò, A.; Venturini, E.; Zaccagnino, A.; Mattarei, A.; Carraretto, L.; et al. Direct Pharmacological Targeting of a Mitochondrial Ion Channel Selectively Kills Tumor Cells In Vivo. Cancer Cell 2017, 31, 516-531. [CrossRef]

28. Kacik, M.; Oliván-Viguera, A.; Köhler, R. Modulation of K(Ca)3.1 channels by eicosanoids, omega-3 fatty acids, and molecular determinants. PLoS ONE 2014, 9, e112081. [CrossRef]

29. Bauer, D.; Werth, F.; Nguyen, H.A.; Kiecker, F.; Eberle, J. Critical role of reactive oxygen species (ROS) for synergistic enhancement of apoptosis by vemurafenib and the potassium channel inhibitor TRAM-34 in melanoma cells. Cell Death Dis. 2017, 8, e2594. [CrossRef] 
30. Busch, A.E.; Suessbrich, H.; Kunzelmann, K.; Hipper, A.; Greger, R.; Waldegger, S.; Mutschler, E.; Lindemann, B.; Lang, F. Blockade of epithelial $\mathrm{Na}^{+}$channels by triamterenes-Underlying mechanisms and molecular basis. Pflugers Arch. 1996, 432, 760-766. [CrossRef]

31. Planer, J.D.; Hulverson, M.A.; Arif, J.A.; Ranade, R.M.; Don, R.; Buckner, F.S. Synergy testing of FDA-approved drugs identifies potent drug combinations against Trypanosoma cruzi. PLoS Negl. Trop. Dis. 2014, 8, e2977. [CrossRef]

32. Kandel, C.; Schmidt, P.; Perniss, A.; Keshavarz, M.; Scholz, P.; Osterloh, S.; Althaus, M.; Kummer, W.; Deckmann, K. ENaC in Cholinergic Brush Cells. Front. Cell Dev. Biol. 2018, 6, 89. [CrossRef]

33. Canessa, C.M.; Schild, L.; Buell, G.; Thorens, B.; Gautschi, I.; Horisberger, J.D.; Rossier, B.C. Amiloride-sensitive epithelial $\mathrm{Na}+$ channel is made of three homologous subunits. Nature 1994, 367, $463-467$. [CrossRef] [PubMed]

34. Pawson, A.J.; Sharman, J.L.; Benson, H.E.; Faccenda, E.; Alexander, S.P.H.; Buneman, O.P.; Davenport, A.P.; McGrath, J.C.; Peters, J.A.; Southan, C.; et al. The IUPHAR/BPS Guide to PHARMACOLOGY: An expert-driven knowledgebase of drug targets and their ligands. Nucleic Acids Res. 2014, 42, D1098-D1106. [CrossRef]

35. Ramzan, I. Phytotherapies: Efficacy, Safety, and Regulation; Wiley: Hoboken, NJ, USA, 2015; ISBN 978-1-118-26806-3.

36. Wörsdörfer, P.; Maxeiner, S.; Markopoulos, C.; Kirfel, G.; Wulf, V.; Auth, T.; Urschel, S.; von Maltzahn, J.; Willecke, K. Connexin expression and functional analysis of gap junctional communication in mouse embryonic stem cells. Stem Cells 2008, 26, 431-439. [CrossRef]

37. Vessey, J.P.; Lalonde, M.R.; Mizan, H.A.; Welch, N.C.; Kelly, M.E.M.; Barnes, S. Carbenoxolone inhibition of voltage-gated Ca channels and synaptic transmission in the retina. J. Neurophysiol. 2004, 92, 1252-1256. [CrossRef]

38. Alvarez, J.; Montero, M.; Garcia-Sancho, J. High affinity inhibition of $\mathrm{Ca}(2+)$-dependent $\mathrm{K}^{+}$channels by cytochrome P-450 inhibitors. J. Biol. Chem. 1992, 267, 11789-11793. [PubMed]

39. Chang, H.-T.; Chen, W.-C.; Chen, J.-S.; Lu, Y.-C.; Hsu, S.-S.; Wang, J.-L.; Cheng, H.-H.; Cheng, J.-S.; Jiann, B.-P.; Chiang, A.-J.; et al. Effect of miconazole on intracellular $\mathrm{Ca}^{2+}$ levels and proliferation in human osteosarcoma cells. Life Sci. 2005, 76, 2091-2101. [CrossRef] [PubMed]

40. Botana, L.M. Seafood and Freshwater Toxins: Pharmacology, Physiology, and Detection; CRC Press: Boca Raton, FL, USA, 2014; ISBN 9781466505148.

41. Ko, C.; Park, W.-J.; Park, S.; Kim, S.; Windisch, M.P.; Ryu, W.-S. The FDA-approved drug irbesartan inhibits HBV-infection in HepG2 cells stably expressing sodium taurocholate co-transporting polypeptide. Antivir. Ther. 2015, 20, 835-842. [CrossRef] [PubMed]

42. Comes, N.; Serrano-Albarrás, A.; Capera, J.; Serrano-Novillo, C.; Condom, E.; Ramón, Y.; Cajal, S.; Ferreres, J.C.; Felipe, A. Involvement of potassium channels in the progression of cancer to a more malignant phenotype. Biochim. Biophys. Acta 2015, 1848, 2477-2492. [CrossRef] [PubMed]

43. Marshall, H.T.; Djamgoz, M.B.A. Immuno-Oncology: Emerging Targets and Combination Therapies. Front. Oncol. 2018, 8, 315. [CrossRef] [PubMed]

44. D'Arcangelo, D.; Nicodemi, E.M.; Facchiano, A. Letter to the editor: "Ion channels in brain metastasis"-Ion channels in cancer set up and metastatic progression. Int. J. Mol. Sci. 2017, 18, 718. [CrossRef]

45. He, M.; Liu, S.; Gallolu Kankanamalage, S.; Borromeo, M.D.; Girard, L.; Gazdar, A.F.; Minna, J.D.; Johnson, J.E.; Cobb, M.H. The Epithelial Sodium Channel $(\alpha \mathrm{ENaC})$ Is a Downstream Therapeutic Target of ASCL1 in Pulmonary Neuroendocrine Tumors. Transl. Oncol. 2018, 11, 292-299. [CrossRef] [PubMed]

46. Varley, K.E.; Gertz, J.; Roberts, B.S.; Davis, N.S.; Bowling, K.M.; Kirby, M.K.; Nesmith, A.S.; Oliver, P.G.; Grizzle, W.E.; Forero, A.; et al. Recurrent read-through fusion transcripts in breast cancer. Breast Cancer Res. Treat. 2014, 146, 287-297. [CrossRef] [PubMed]

47. Jarzab, B.; Wiench, M.; Fujarewicz, K.; Simek, K.; Jarzab, M.; Oczko-Wojciechowska, M.; Wloch, J.; Czarniecka, A.; Chmielik, E.; Lange, D.; et al. Gene expression profile of papillary thyroid cancer: Sources of variability and diagnostic implications. Cancer Res. 2005, 65, 1587-1597. [CrossRef]

48. Willis, S.; Villalobos, V.M.; Gevaert, O.; Abramovitz, M.; Williams, C.; Sikic, B.I.; Leyland-Jones, B. Single Gene Prognostic Biomarkers in Ovarian Cancer: A Meta-Analysis. PLoS ONE 2016, 11, e0149183. [CrossRef] [PubMed] 
49. Zhang, Z.; Chen, J.; He, Y.; Zhan, X.; Zhao, R.; Huang, Y.; Xu, H.; Zhu, Z.; Liu, Q. miR-125b inhibits hepatitis $B$ virus expression in vitro through targeting of the SCNN1A gene. Arch. Virol. 2014, 159, 3335-3343. [CrossRef] [PubMed]

50. Kappelmann, M.; Kuphal, S.; Meister, G.; Vardimon, L.; Bosserhoff, A.-K. MicroRNA miR-125b controls melanoma progression by direct regulation of c-Jun protein expression. Oncogene 2013, 32, 2984-2991. [CrossRef]

51. D'Arcangelo, D.; Giampietri, C.; Muscio, M.; Scatozza, F.; Facchiano, F.; Facchiano, A. WIPI1, BAG1, and PEX3 Autophagy-Related Genes Are Relevant Melanoma Markers. Oxid. Med. Cell. Longev. 2018, 2018, 1471682. [CrossRef]

52. Kondratskyi, A.; Kondratska, K.; Skryma, R.; Klionsky, D.J.; Prevarskaya, N. Ion channels in the regulation of autophagy. Autophagy 2018, 14, 3-21. [CrossRef]

53. Mandy, S.J.; Garrott, T.C. Miconazole treatment for severe dermatophytoses. JAMA 1974, 230, $72-75$. [CrossRef]

54. Hatton, C.J.; Peers, C. Effects of cytochrome P-450 inhibitors on ionic currents in isolated rat type I carotid body cells. Am. J. Physiol. 1996, 271, C85-C92. [CrossRef] [PubMed]

55. Verdoliva, V.; Senatore, C.; Polci, M.L.; Rossi, S.; Cordella, M.; Carlucci, G.; Marchetti, P.; Antonini-Cappellini, G.; Facchiano, A.; D'Arcangelo, D.; et al. Differential Denaturation of Serum Proteome Reveals a Significant Amount of Hidden Information in Complex Mixtures of Proteins. PLoS ONE 2013, 8, e57104. [CrossRef] [PubMed]

56. Rossi, S.; Cordella, M.; Tabolacci, C.; Nassa, G.; D’Arcangelo, D.; Senatore, C.; Pagnotto, P.; Magliozzi, R.; Salvati, A.; Weisz, A.; et al. TNF-alpha and metalloproteases as key players in melanoma cells aggressiveness. J. Exp. Clin. Cancer Res. 2018, 37, 326. [CrossRef] [PubMed]

57. Haapajärvi, T.; Pitkänen, K.; Laiho, M. Human melanoma cell line UV responses show independency of p53 function. Cell Growth Differ. 1999, 10, 163-171. [PubMed]

58. Raisova, M.; Hossini, A.M.; Eberle, J.; Riebeling, C.; Wieder, T.; Sturm, I.; Daniel, P.T.; Orfanos, C.E.; Geilen, C.C. The Bax/Bcl-2 ratio determines the susceptibility of human melanoma cells to CD95/Fas-mediated apoptosis. J. Invest. Dermatol. 2001, 117, 333-340. [CrossRef] [PubMed]

59. Mun, Y.-J.; Lee, S.-W.; Jeong, H.-W.; Lee, K.-G.; Kim, J.-H.; Woo, W.-H. Inhibitory effect of miconazole on melanogenesis. Biol. Pharm. Bull. 2004, 27, 806-809. [CrossRef]

60. Wu, C.-H.; Jeng, J.-H.; Wang, Y.-J.; Tseng, C.-J.; Liang, Y.-C.; Chen, C.-H.; Lee, H.-M.; Lin, J.-K.; Lin, C.-H.; Lin, S.-Y.; et al. Antitumor effects of miconazole on human colon carcinoma xenografts in nude mice through induction of apoptosis and G0/G1 cell cycle arrest. Toxicol. Appl. Pharmacol. 2002, 180, 22-35. [CrossRef]

61. Wang, Y.-J.; Jeng, J.-H.; Chen, R.-J.; Tseng, H.; Chen, L.-C.; Liang, Y.-C.; Lin, C.-H.; Chen, C.-H.; Chu, J.-S.; Ho, W.-L.; et al. Ketoconazole potentiates the antitumor effects of nocodazole: In vivo therapy for human tumor xenografts in nude mice. Mol. Carcinog. 2002, 34, 199-210. [CrossRef] [PubMed]

62. Yuan, S.-Y.; Shiau, M.-Y.; Ou, Y.-C.; Huang, Y.-C.; Chen, C.-C.; Cheng, C.-L.; Chiu, K.-Y.; Wang, S.-S.; Tsai, K.-J. Miconazole induces apoptosis via the death receptor 5-dependent and mitochondrial-mediated pathways in human bladder cancer cells. Oncol. Rep. 2017, 37, 3606-3616. [CrossRef] [PubMed]

63. Roan, C.-J.; Chou, C.-T.; Liang, W.-Z.; Chang, H.-T.; Kuo, D.-H.; Kuo, C.-C.; Chen, F.-A.; Shieh, P.; Jan, C.-R. Effect of Miconazole on $\left[\mathrm{Ca}^{2+}\right] \mathrm{i}$ and Cytotoxicity in ZR-75-1 Human Breast Cancer Cells. Chin. J. Physiol. 2015, 58, 377-384. [CrossRef] [PubMed]

64. Torikai, M.; Ibara, S.; Ieiri, S.; Hamada, T.; Noguchi, H.; Sueyoshi, K.; Fukuda, T.; Abeyama, K. Prophylactic efficacy of enteral miconazole administration for neonatal intestinal perforation and its potential mechanism. Pediatr. Surg. Int. 2016, 32, 953-957. [CrossRef] [PubMed]

65. Li, N.; Song, X.; Wu, L.; Zhang, T.; Zhao, C.; Yang, X.; Shan, L.; Yu, P.; Sun, Y.; Wang, Y.; et al. Miconazole stimulates post-ischemic neurogenesis and promotes functional restoration in rats. Neurosci. Lett. 2018, 687, 94-98. [CrossRef]

66. Singh, M.; Saha, R.K.; Saha, H.; Parhi, J. Effect of miconazole nitrate on immunological response and its preventive efficacy in Labeo rohita fingerlings against oomycetes Saprolegnia parasitica. J. Fish Dis. 2018, 41, 1539-1548. [CrossRef] [PubMed] 
67. Lu, X.; He, S.-Y.; Li, Q.; Yang, H.; Jiang, X.; Lin, H.; Chen, Y.; Qu, W.; Feng, F.; Bian, Y.; et al. Investigation of multi-target-directed ligands (MTDLs) with butyrylcholinesterase (BuChE) and indoleamine 2,3-dioxygenase 1 (IDO1) inhibition: The design, synthesis of miconazole analogues targeting Alzheimer's disease. Bioorg. Med. Chem. 2018, 26, 1665-1674. [CrossRef]

68. Pemberton, M.N. Morbidity and mortality associated with the interaction of miconazole oral gel and warfarin. Br. Dent. J. 2018, 225, 129-132. [CrossRef]

69. Liang, G.; Liu, M.; Wang, Q.; Shen, Y.; Mei, H.; Li, D.; Liu, W. Itraconazole exerts its anti-melanoma effect by suppressing Hedgehog, Wnt, and PI3K/mTOR signaling pathways. Oncotarget 2017, 8, 28510-28525. [CrossRef]

70. Lee, S.W.; Kim, Y.C.; Kim, D.K.; Yoon, T.Y.; Park, H.J.; Cinn, Y.W. Fungal melanonychia. J. Dermatol. 2004, 31 , 904-909. [CrossRef] [PubMed]

71. Schwartz, R.A. Superficial fungal infections. Lancet 2004, 364, 1173-1182. [CrossRef]

72. Chung, B.Y.; Kim, S.Y.; Jung, J.M.; Won, C.H.; Choi, J.H.; Lee, M.W.; Chang, S.E. The antimycotic agent clotrimazole inhibits melanogenesis by accelerating ERK and PI3K-/Akt-mediated tyrosinase degradation. Exp. Dermatol. 2015, 24, 386-388. [CrossRef] [PubMed]

73. Talantov, D.; Mazumder, A.; Yu, J.X.; Briggs, T.; Jiang, Y.; Backus, J.; Atkins, D.; Wang, Y. Novel genes associated with malignant melanoma but not benign melanocytic lesions. Clin. Cancer Res. 2005, 11, 7234-7242. [CrossRef] [PubMed]

74. Mandrekar, J.N. Receiver operating characteristic curve in diagnostic test assessment. J. Thorac. Oncol. 2010, 5, 1315-1316. [CrossRef] [PubMed]

75. Raskin, L.; Fullen, D.R.; Giordano, T.J.; Thomas, D.G.; Frohm, M.L.; Cha, K.B.; Ahn, J.; Mukherjee, B.; Johnson, T.M.; Gruber, S.B. Transcriptome profiling identifies HMGA2 as a biomarker of melanoma progression and prognosis. J. Investig. Dermatol. 2013, 133, 2585-2592. [CrossRef] [PubMed]

76. Riker, A.I.; Enkemann, S.A.; Fodstad, O.; Liu, S.; Ren, S.; Morris, C.; Xi, Y.; Howell, P.; Metge, B.; Samant, R.S.; et al. The gene expression profiles of primary and metastatic melanoma yields a transition point of tumor progression and metastasis. BMC Med. Genomics 2008, 1, 13. [CrossRef]

77. Chen, H.; Sharp, B.M. Content-rich biological network constructed by mining PubMed abstracts. BMC Bioinform. 2004, 5, 147.

78. Facchiano, F.; D'Arcangelo, D.; Lentini, A.; Rossi, S.; Senatore, C.; Pannellini, T.; Tabolacci, C.; Facchiano, A.M.; Facchiano, A.; Beninati, S. Tissue transglutaminase activity protects from cutaneous melanoma metastatic dissemination: An in vivo study. Amino Acids 2013, 44, 53-61. [CrossRef]

79. D'Arcangelo, D.; Facchiano, F.; Nassa, G.; Stancato, A.; Antonini, A.; Rossi, S.; Senatore, C.; Cordella, M.; Tabolacci, C.; Salvati, A.; et al. PDGFR-alpha inhibits melanoma growth via CXCL10/IP-10: A multi-omics approach. Oncotarget 2016, 7, 77257. [CrossRef] 